\title{
Land-Based Convection Effects on Formation of Tropical Cyclone Mekkhala (2008)
}

\author{
MYUNG-SOOK PARK, ${ }^{a}$ MYONG-IN LEE, AND DONGMIN KIM \\ School of Urban and Environmental Engineering, Ulsan National Institute of Science and Technology, Ulsan, South Korea
}

MiCHAEL M. BELL

Department of Atmospheric Science, Colorado State University, Fort Collins, Colorado

DONG-HYUN CHA

School of Urban and Environmental Engineering, Ulsan National Institute of Science and Technology, Ulsan, South Korea

\author{
RUSSELL L. ELSBERRY
}

Department of Meteorology, Naval Postgraduate School, Monterey, California

(Manuscript received 4 May 2016, in final form 19 December 2016)

\begin{abstract}
The effects of land-based convection on the formation of Tropical Storm Mekkhala (2008) off the west coast of the Philippines are investigated using the Weather Research and Forecasting Model with 4-km horizontal grid spacing. Five simulations with Thompson microphysics are utilized to select the control-land experiment that reasonably replicates the observed sea level pressure evolution. To demonstrate the contribution of the land-based convection, sensitivity experiments are performed by changing the land of the northern Philippines to water, and all five of these no-land experiments fail to develop Mekkhala.

The Mekkhala tropical depression develops when an intense, well-organized land-based mesoscale convective system moves offshore from Luzon and interacts with an oceanic mesoscale system embedded in a strong monsoon westerly flow. Because of this interaction, a midtropospheric mesoscale convective vortex (MCV) organizes offshore from Luzon, where monsoon convection continues to contribute to low-level vorticity enhancement below the midlevel vortex center. In the no-land experiments, widespread oceanic convection induces a weaker midlevel vortex farther south in a strong vertical wind shear zone and subsequently farther east in a weaker monsoon vortex region. Thus, the monsoon convection-induced low-level vorticity remained separate from the midtropospheric $\mathrm{MCV}$, which finally resulted in a failure of the low-level spinup. This study suggests that land-based convection can play an advantageous role in TC formation by influencing the intensity and the placement of the incipient midtropospheric MCV to be more favorable for TC low-level circulation development.
\end{abstract}

\section{Introduction}

As originally defined by Gray $(1968,1975)$, favorable environmental conditions for tropical cyclone (TC) formation include a sufficiently warm upper ocean (e.g., sea surface temperature $>26^{\circ} \mathrm{C}$ ), convective

\footnotetext{
${ }^{\text {a }}$ Current affiliation: Korea Ocean Satellite Center, Korea Institute of Ocean Science and Technology, Ansan, South Korea.
}

Corresponding author e-mail: Dr. Myong-In Lee, milee@unist. ac.kr instability in the lower atmosphere with large relative humidity in the middle troposphere, large cyclonic absolute vorticity in the lower troposphere, and weak vertical wind shear. The first two "thermodynamic conditions" are related to multitime-scale oceanic conditions and atmospheric variability. The last two "dynamic conditions" of large-scale vorticity and/or wind shear can vary with preexisting synoptic-scale disturbances, such as the monsoon trough (Lander 1994), monsoon depression (Harr et al. 1996), and easterly waves (Reed and Recker 1971). While TC formation is generally thought to be involved with atmospheric and oceanic processes, the purpose of this paper is to 
highlight a case of near-coastal TC formation that additionally involves land physical processes.

Mesoscale convective systems (MCS) embedded within a preexisting synoptic disturbance may also contribute to TC formation. Ritchie and Holland (1997) emphasized the role of midlevel mesoscale convective vortices (MCV) within extensive MCS stratiform regions in intensifying the large-scale cyclonic circulation. Nolan (2007) showed that moistening of the environment by the repeated occurrence of convective cells in a developing depression facilitates the conversion of the vortex to a TC. Hendricks et al. (2004) and Montgomery et al. (2006) suggested that the updrafts of deep convection in the vorticity-rich environment of a preexisting depression can develop vertical vorticity anomalies collocated with the updrafts, which are called vortical hot towers (VHTs). The collective effects of multiple VHTs were proposed to lead to the formation of a single larger vortex through merger and aggregation with a sufficiently enhanced surface cyclonic circulation to become self-sustaining.

Field observation programs such as Tropical Cyclone Structure 2008 (TCS-08; Elsberry and Harr 2008) and PreDepression Investigation of Cloud-Systems in the Tropics (PREDICT; Montgomery et al. 2012) were organized to verify the TC formation theories suggested by numerical simulations. For example, Bell and Montgomery (2010) have provided observational evidence of meso-beta-scale VHTs in the convective region prior to the formation of Hagupit (2008) during TCS-08 based on the analyses of high-resolution aircraft Doppler radar observations. Using the same radar data, Park and Elsberry (2013) and Park et al. (2013) emphasized that the convection-driven low-level latent heating maximum prior to the formation of Nuri (2008) was favorable for low-level spinup. Using the dropsonde observations during PREDICT, Davis and Ahijevych (2012) emphasized that the vertical alignment of mesoscale cyclonic circulations, coupled with quasipersistent deep moist convection, appeared to be essential for the formation of Tropical Storms Karl and Matthew in the Atlantic during 2010. Recently, Penny et al. (2015) have shown that a seemingly favorable disturbance during TCS-08 failed to develop due to vertical wind shear and vertical misalignment of the circulations.

Each of these previous studies has investigated the physical mechanisms by which tropical oceanic convection contributes to open-ocean TC formations, but it is notable that a number of TC formations throughout all ocean basins (Gray 1975) occur near a coastal area or an island. An unexpected formation of a near-coastal TC may have an immediate threat to human life, economy, and agriculture since the TC landfall can occur just a few days after the formation. Therefore, better understanding and improved predictions of near-coastal TC formation processes are necessary to establish an effective early public warning system.

A primary TC formation region with potential land effects is the South China Sea in the western North Pacific, with the Asian continent to the west and the Philippine Islands to the east. Under the influence of the large-scale westerly flow during the summer, wellorganized monsoon-type oceanic convective systems typically evolve off the west coast of the Philippines (Johnson et al. 2005; Park et al. 2011). Dynamically convective updrafts in the low-level vorticity-rich monsoon environment contribute to low-level vorticity enhancement.

It is hypothesized that TC development may be favored offshore over the South China Sea due to the existence of an additional heat source from deep convection (i.e., VHTs) over the adjacent land (Ho et al. 2008), even though vertical wind shear associated with strong monsoon westerly winds (Kim et al. 2008) would seem to be unfavorable. This hypothesis is motivated by the observational study of Park et al. (2015), who examined the formation of Tropical Storm (TS) Mekkhala (2008) over the South China Sea west of the Philippines using ECMWF Year of Tropical Convection (YOTC) reanalyses, Multifunctional Transport Satellite-1R (MTSAT-1R), and TRMM observations. Although the strengthened large-scale westerly flow and precursor synoptic-scale circulations had important contributions, Park et al. concluded that the diurnally varying convection over both the land (Philippines) and the ocean had an essential role in inducing the prolonged convective burst that led to the development of the pre-Mekkhala depression. A limitation of the Park et al. study was that coarse-resolution global analyses could not resolve the critical role of mesoscale dynamics and kinematics in intensifying the preexisting synoptic circulation to tropical depression (TD) strength. To expand on the observational study of Park et al. (2015), this paper presents a numerical modeling study of TS Mekkhala formation using high-resolution convection-allowing Weather Research and Forecasting (WRF; Skamarock et al. 2008) Model simulations.

The overall objective of this paper is to advance understanding of the role of convection over land in TC formation, and specifically how a MCS that initiated over the northern Philippines makes an essential contribution to intensify the pre-Mekkhala precursor vortex to the TD stage. A description of the model setup and sensitivity experiments on the effects of land is given in section 2. A validation of the numerical experiments on TC development is presented in section 3 . In section 4 , 


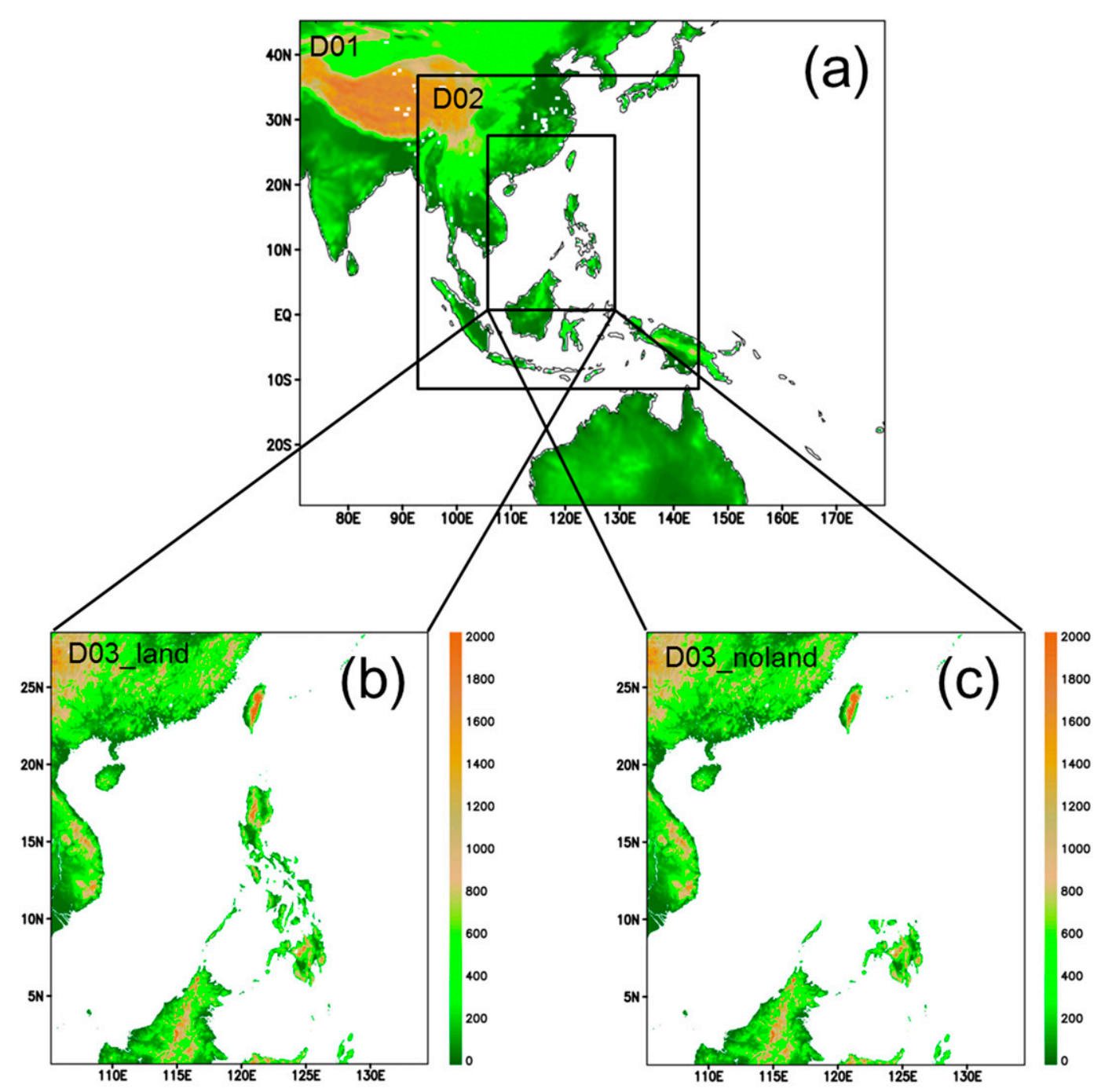

FIG. 1. (a) Model setup of three domains (D01-D03) for all WRF simulations, and topographies of D03 for the (b) control and (c) NoL experiments.

the impact of land-based convection on the TC formation is demonstrated based on a comparison of control-land versus no-land experiments. A summary and conclusions are given in section 5 .

\section{Methodology}

\section{a. Model setup}

This study employs the Advanced Research version of WRF (version 3.4; Skamarock et al. 2008). Two grid nests with 4-km horizontal spacing on the innermost nest are employed to properly represent the convection (Fig. 1a). The outer domain has a horizontal grid spacing of $36 \mathrm{~km}$ with $330 \times 250$ grid points in the $x$ and $y$ directions. The center grid spacing is $12 \mathrm{~km}$ with $250 \times 472$ grid points, and there are $802 \times 802$ grid points on the 4-km inner nest. Two-way interaction is employed for all nests. All domains have 28 vertical eta levels.

Initial and boundary conditions are obtained from sixhourly National Centers for Environmental Prediction Final Analyses (NCEP FNL) with a $1^{\circ} \times 1^{\circ}$ resolution. The pre-Mekkhala depression forms at 1800 UTC 27 September according to the Regional Specialized Meteorological Center (RSMC) Tokyo-Typhoon Center best track. According to Park et al. (2015), the TC formation was attributed to the interaction around 1200 UTC 25 September between land-based convection and oceanic convection. To determine the best initial conditions for the WRF Model to reproduce both the evolution of the pre-Mekkhala disturbance and the convection over the land and the South China Sea, 96-h WRF integrations 
TABLE 1. WRF Model configurations for the CTL and NoL sensitivity experiments, MP scheme, land mask of the northern Philippines, and the model's performance during the integration. All simulations were initialized at 0000 UTC 24 Sep. For the sensitivity of the land impact on TC formation, a CTL experiment should be compared only with an NoL experiment with the same microphysics.

\begin{tabular}{lllcl}
\hline \hline & Name & MP & Northern Philippines land mask & TC formation \\
\hline CTL & CTL & Thompson $\left(N_{c}=100\right)$ & Land & Developing \\
& CTL150 & Thompson $\left(N_{c}=150\right)$ & Land & Developing \\
& CTL200 & Thompson $\left(N_{c}=200\right)$ & Land & Underdeveloped \\
& CTL250 & Thompson $\left(N_{c}=250\right)$ & Land & Underdeveloped \\
NoL & CTL300 & Thompson $\left(N_{c}=300\right)$ & Land & Developing \\
& NoL & Thompson $\left(N_{c}=100\right)$ & Water & Water development \\
& NoL150 & Thompson $\left(N_{c}=150\right)$ & Water & No development \\
& NoL200 & Thompson $\left(N_{c}=200\right)$ & Water development & No development \\
& NoL250 & Thompson $\left(N_{c}=250\right)$ & Water & No development \\
& NoL300 & Thompson $\left(N_{c}=300\right)$ & &
\end{tabular}

were initiated every $12 \mathrm{~h}$ from 0000 UTC 22 September through 0000 UTC 24 September 2008. The latest simulation that was initiated at 0000 UTC 24 September 2008 best represented the developing $\mathrm{TC}^{1}$ and was selected for this study.

After testing various options for the WRF Model physics, the Thompson et al. (2004) microphysics parameterization was selected due to its better performance in reproducing the TC development compared to other schemes. The WSM6 and WRF double-moment 5-class microphysics (MP) scheme (WDM5) options did develop a weak low-level cyclonic circulation related to the TC (not shown). In these simulations, the convection was generally of shorter duration and did not persist enough to lead to a strong development.

Other model physics representations include the fifthgeneration Pennsylvania State University-National Center for Atmospheric Research (NCAR) Mesoscale Model (MM5) similarity-layer scheme (Beljaars 1995), the Yonsei University boundary layer scheme (Noh et al. 2003; Hong et al. 2006), the Noah land surface scheme (Chen and Dudhia. 2001), and the Kain-Fritsch cumulus scheme (Kain 2004) on the 36- and 12-km grids only. Radiative processes are calculated every $900 \mathrm{~s}$ using the Rapid Radiative Transfer Model longwave and shortwave schemes (Mlawer et al. 1997). The terrain elevations are from the global 30 arc s elevation dataset from the U.S. Geological Survey (USGS), and the land use is based on the 24-category data of the USGS. In the unmodified topography control simulations, the mountains in the northern Philippines are well represented (Fig. 1b). The highest elevation over the Philippines on the inner

\footnotetext{
${ }^{1}$ The earlier simulations were not successful since they produced a much weaker midtropospheric mesoscale vortex off the west coast of Luzon and deepening of sea level pressure was absent.
}

mesh 3 is above $2000 \mathrm{~m}$, which reasonably corresponds to the elevation of Pulog Mountain (2928 m) on Luzon.

\section{b. Sensitivity experiment design and storm tracking}

To test the effects of the land-based convection on storm development, multiple sensitivity tests were conducted. First, five control-land experiments were performed by perturbing the cloud droplet number concentration $\left(N_{c}\right)$ in the Thompson microphysics scheme. The default concentration in the Thompson microphysics scheme $\left(100 \mathrm{~cm}^{-3}\right)$ is appropriate for the open sea, and $300 \mathrm{~cm}^{-3}$ is appropriate over the continent (Thompson et al. 2004). Since our case deals with both an oceanic MCS and a land-based MCS, the parameter was modified between the two threshold values in five control experiments (Table 1) labeled as CTL, CTL150, CTL200, CTL250, and CTL300, respectively.

Here, our purpose of cloud microphysics modulation is limited to testing the sensitivity to the distribution of convection in multiple TC simulations. The effect of such a modulation is believed to be stochastic in this case, which provides a limited ensemble of simulations that develop slightly different mesoscale convective patterns from the same initial and synoptic conditions.

The final objective is to show the effects of land surface heating and sea-breeze convergence that produce a well-timed, well-placed MCS (section 5), rather than the aerosols or the specific character of the convective microphysics. In the WRF preprocessing system, topography on all three domains was modified by changing the land surface type to water to remove the effect of land over the selected region of the northern Philippines shown in Fig. 1c. A four-point bilinear interpolation was applied within the gap between the virtual ocean, where the topography is removed, and the original ocean. In addition, albedo, monthly green fraction, land-use index, and soil type are also treated as water. It is possible that an ensemble among the five control-land simulations 
generated by changing droplet number concentrations may be somewhat underdispersed. Nevertheless, the current hypothesis (positive land impact on TC formation) can be verified via comparisons of the control-land experiment with its paired sensitivity experiment without the land in Table 1, for example, CTL versus NoL, CLT150 versus NoL150, etc.

In the pre-TD stage, it is difficult to define and track the system center and minimum sea level pressure (MSLP) due to the absence of a well-defined low-level center. The 500-hPa mesoscale vortex center is tracked as the maximum in the domain 3 relative vorticity field after a two-dimensional low-bandpass filter is applied. Wavelengths less than $300 \mathrm{~km}$ were filtered out for the center tracking, which was then used to follow the disturbance evolution and to examine the synoptic circulations related to the TC formation.

\section{Results and validation: Control-land experiment}

\section{a. Evolution of TC: Preformation stage versus tropical depression stage}

The validation of the simulated development of the pre-Mekkhala depression will be first described with the simulated fields from the CTL experiment. The simulated rain rates, $850-\mathrm{hPa}$ wind vectors, and sea level pressure in the CTL after $24 \mathrm{~h}$ of model integration are compared in Figs. 2-4 ${ }^{2}$ with the Tropical Rainfall Measuring Mission (TRMM) Multisatellite Precipitation Analysis (TMPA; Huffman et al. 2007) and the corresponding NCEP FNL.

At 0000 UTC (0800 LT) 25 September, two regions with high rain rates $\left(\geq 7 \mathrm{~mm} \mathrm{~h}^{-1}\right)$ are simulated over the ocean (Fig. 2a). The first region of oceanic convection in the middle of the South China Sea is embedded in the synoptic-scale monsoon vortex (SYN1) with southwesterlies, which are weaker in the simulation than the westerly flows crossing the Philippines in the NCEP FNL (Fig. 2b). A second region of oceanic convection off the east coast of the Philippines near $125^{\circ} \mathrm{E}$ is located within a synoptic-scale cyclonic disturbance (SYN2) (Fig. 2c) that is elongated from the northwest (Luzon) to the southeast (over the Philippine Sea). While the locations of the two simulated oceanic convection regions within the different synoptic-scale circulations are qualitatively similar to the observations, the WRF simulation has a more intense cellular convection than the observed convection. The light rain area in the oceanic

\footnotetext{
${ }^{2}$ The time interval between the figures is irregular to properly capture the critical synoptic-scale and convective evolution.
}

convection over the South China Sea (Fig. 2a) is much smaller in the model than in the satellite retrieval (Fig. 2b). This discrepancy is in part due to the different horizontal resolution between the simulated precipitation $(4 \mathrm{~km})$ and the TRMM satellite rain retrieval $\left(0.25^{\circ}\right)$, but it also may be due to the WRF Model not properly organizing the mesoscale convection system within the monsoon (Snively and Gallus 2014). In addition, the WRF Model simulates higher rain rates off the east coast of Philippines than in the TRMM observations.

In Figs. $2 c$ and $2 d$, the vertical structures of the two synoptic-scale circulations associated with convective regions are depicted from the filtered WRF simulations (explained in section 2b). The broad but shallow (below $500 \mathrm{hPa}$ ) region of low-level cyclonic vorticity associated with the monsoon flow over the South China Sea is simulated reasonably well in comparison with the NCEP FNL. ${ }^{3}$ In addition, the cyclonic vorticity maximum at low levels off the east coast of Philippines is elongated with another cyclonic vorticity maximum farther to the southeast (Fig. 2c). The similar horizontal organization of the low-level vortex was seen in the NCEP FNL (Fig. 2d). Park et al. (2015) attribute the pre-Mekkhala elongated precursor (SYN2 in Figs. $2 \mathrm{c}$ and $2 \mathrm{~d}$ ) to the interaction between the northeasterlies in the northwest quadrant of Tropical Storm Jangmi with the monsoon westerlies. Overall, the WRF simulation reasonably reproduced the SYN2 midlevel vortex that was displaced westward from the low-level vortex (Fig. 2c).

Twelve hours later ( $24 \mathrm{~h}$ into the forecast) in the evening (2000 LT 25 September), the WRF Model simulated an intense MCS with heavy rain rates over Luzon $[\mathrm{MCS}(\mathrm{L})]$ in advance of SYN2 as it was moving westward. In addition, the model reproduced the weaker oceanic convection $[\mathrm{MCS}(\mathrm{O})]$ in the monsoon region (Fig. 2e), which is generally consistent with the TMPA rain rates (Fig. 2f). In addition to the large-scale monsoonal vortex, the WRF Model simulated a mesoscale organization of the midlevel circulations between two MCSs (Fig. 2g). The WRF simulation reasonably reproduced the midlevel vortex seen in the NCEP FNL (Fig. 2h), although the vortex is closer to Luzon. At this stage, the vorticity maximum to the west of Luzon is mainly associated with the advection of SYN2.

At 1800 UTC 25 September (0200 UTC 26 September), the two separate regions of $\operatorname{MCS}(\mathrm{O})$ and $\operatorname{MCS}(\mathrm{L})$ in the

\footnotetext{
${ }^{3}$ Since the coarse-resolution NCEP FNL has not been filtered, the vorticity ranges of the NCEP FNL and the filtered WRF data are quite different. However, the vorticity distributions of the two sources may be used to compare mesoscale circulations to synopticscale circulations.
} 


\section{$00 Z 25$ SEP}

a) $\operatorname{WRF}(R, U V, S L P)$ OOZ 25SEP

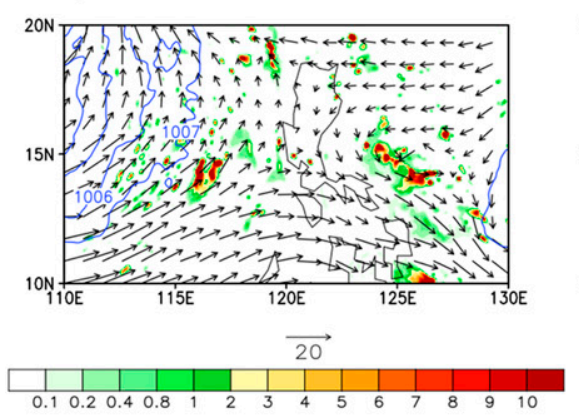

C) WRF(VOR) OOZ 25SEP

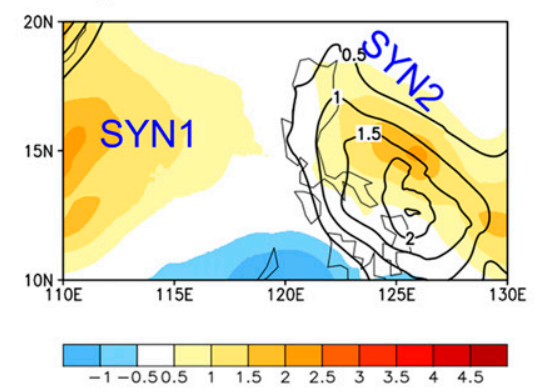

b) OBS(R,UV,SLP) OOZ 25SEP
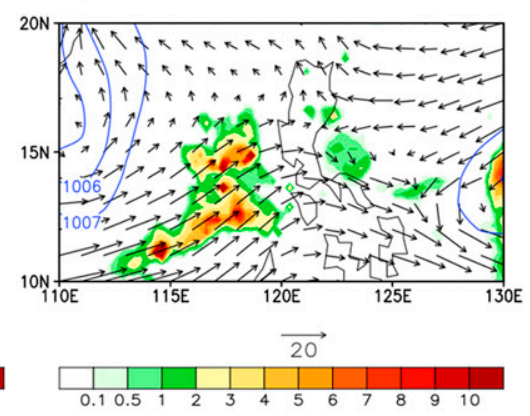

d) OBS(VOR) OOZ 25SEP

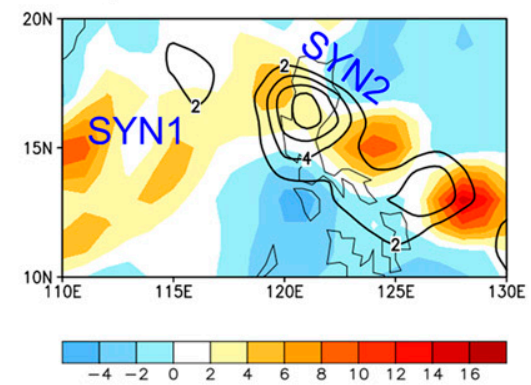

\section{$12 Z 25$ SEP}

e) $\operatorname{WRF}(R, U V, S L P) 12 Z 25 \mathrm{SEP}$

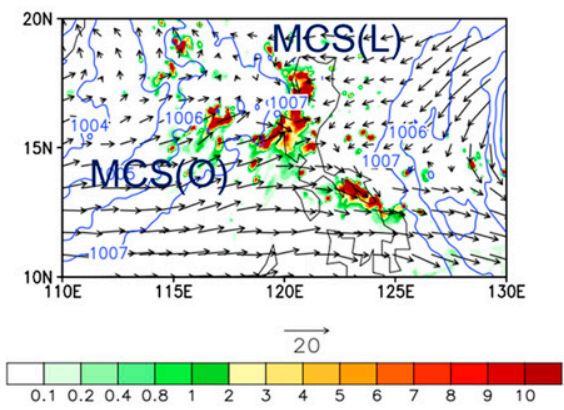

g) $W R F(V O R) 12 Z 25 \mathrm{SEP}$
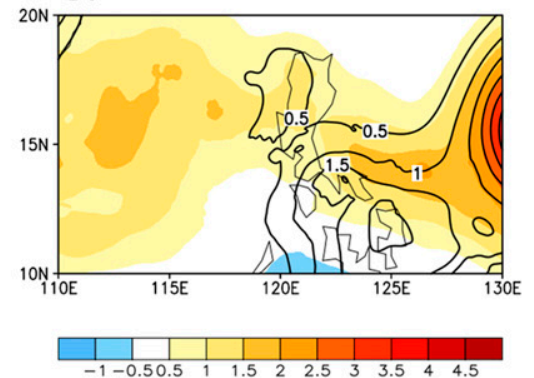

f) $\mathrm{OBS}(R, U V, S L P) 12 Z 25 \mathrm{SEP}$

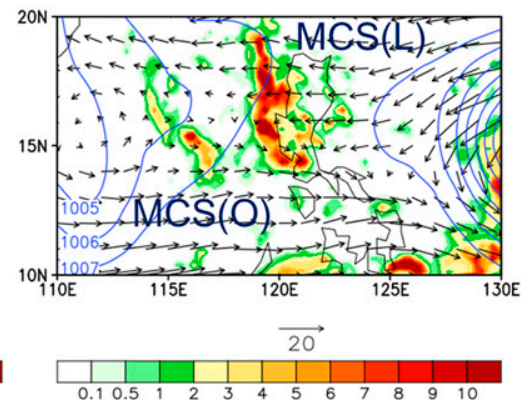

h) OBS(VOR) $12 Z$ 25SEP

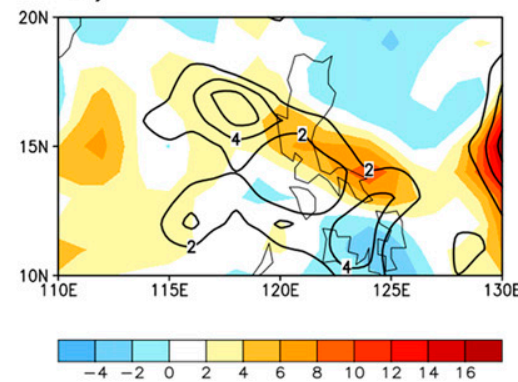

FIG. 2. Comparison of (left) WRF Model integration CTL experiment and (right) NCEP FNL for $0000 \mathrm{UTC} 25 \mathrm{Sep}$ ( $+24-\mathrm{h}$ forecast) in (a) simulated $850-\mathrm{hPa}$ wind $\left(\mathrm{m} \mathrm{s}^{-1}\right.$, vector scale below), SLP (blue contour), and rain rates $\left(\mathrm{mm} \mathrm{h}^{-1}\right.$, color scale below); and (b) corresponding NCEP FNL overlaid with TRMM 3B42 rain rates. Vorticity $\left(10^{-5} \mathrm{~s}^{-1}\right)$ at $850 \mathrm{hPa}$ (shading, scale below) and $500 \mathrm{hPa}$ (contours) from (c) the filtered WRF simulation and (d) NCEP FNL. (e)-(h) As in (a)-(d), but for 1200 UTC 25 Sep. Two important synoptic precursors are indicated as SYN1 and SYN2; also shown are $\mathrm{MCS}(\mathrm{O})$ and $\mathrm{MCS}(\mathrm{L})$. 


\section{$18 Z 25$ SEP}

a) $\operatorname{WRF}(R, U V, S L P) 18 Z$ 25SEP

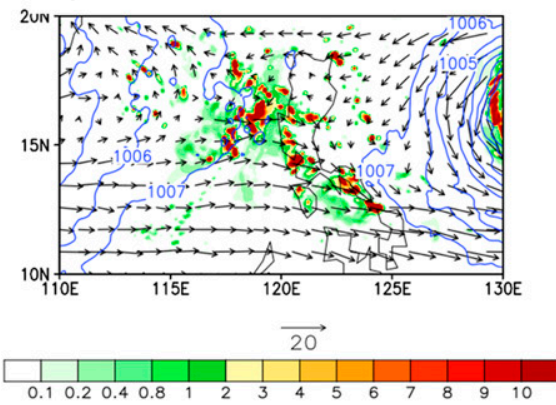

C) WRF(VOR) $18 Z$ 25SEP
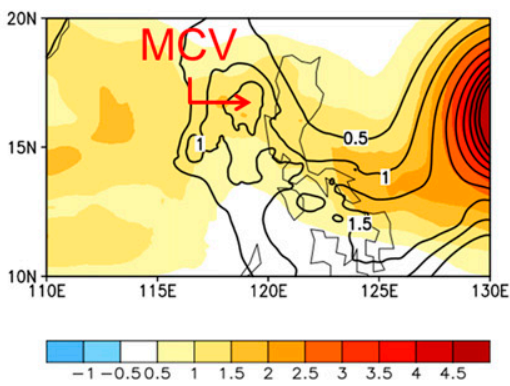

b) $\mathrm{OBS}(\mathrm{R}, \mathrm{UV}, \mathrm{SLP}) 18 \mathrm{Z} 25 \mathrm{SEP}$

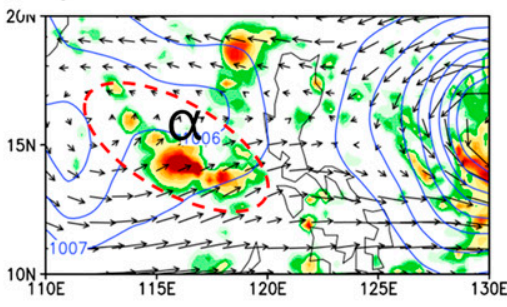

$\overrightarrow{20}$

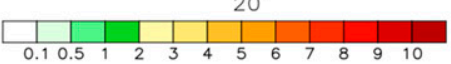

d) OBS(VOR) $18 Z$ 25SEP

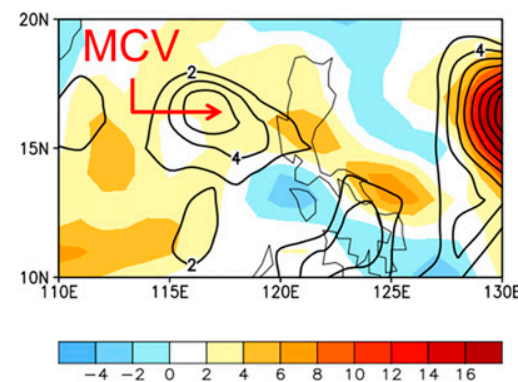

\section{$00 Z 26$ SEP}

e) $\operatorname{WRF}(R, U V, S L P)$ OOZ 26SEP
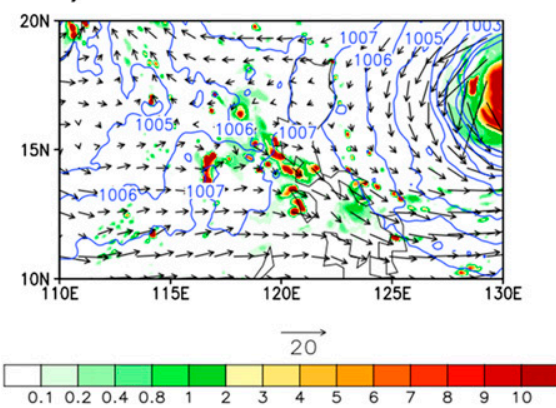

g) WRF(VOR) $00 Z$ 26SEP

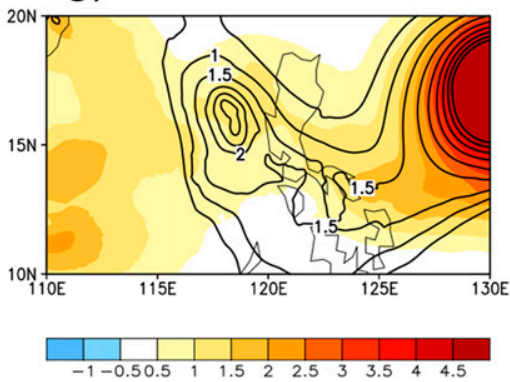

f) $\mathrm{OBS}(R, U V, S L P)$ OOZ 26SEP
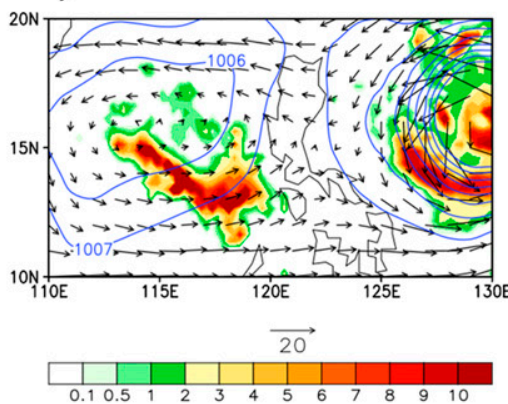

h) OBS(VOR) OOZ 26SEP

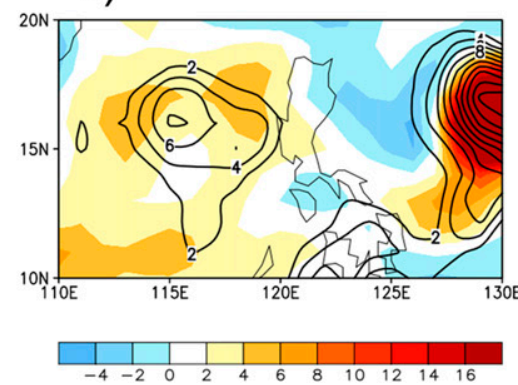

FIG. 3. As in Fig. 2, but at (a)-(d) 1800 UTC 25 Sep and (e)-(h) 0000 UTC 26 Sep when the MCV (indicated by red arrow) that later became the pre-Mekkhala depression intensified between two convective regions. 
a) $\operatorname{WRF}(R, U V, S L P)$ O6Z 27SEP

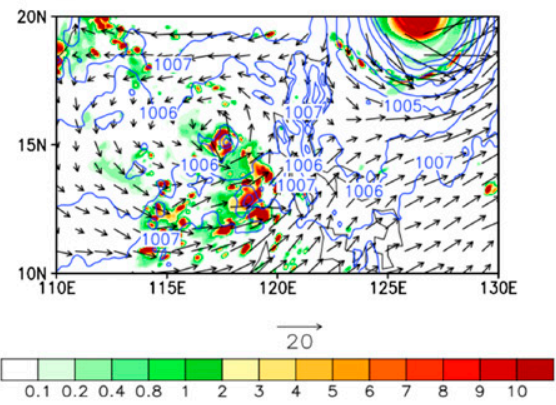

C) WRF(VOR) O6Z 27SEP

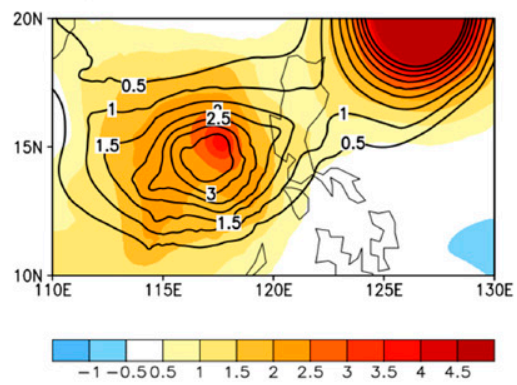

$00 Z 28$ SEP b) OBS(R,UV,SLP) O6Z 27SEP

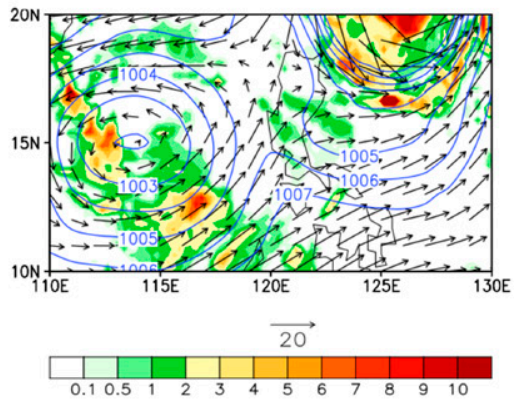

d) OBS(VOR) O6Z 27SEP

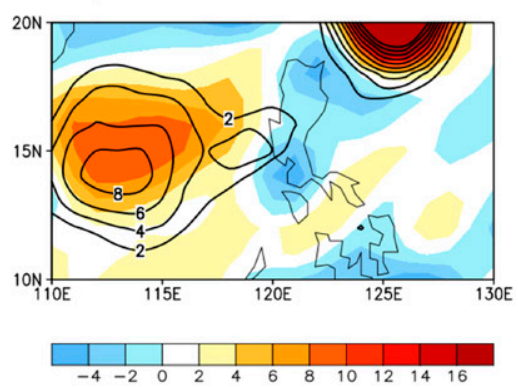

f) $O B S(R, U V, S L P)$ OOZ 28SEP

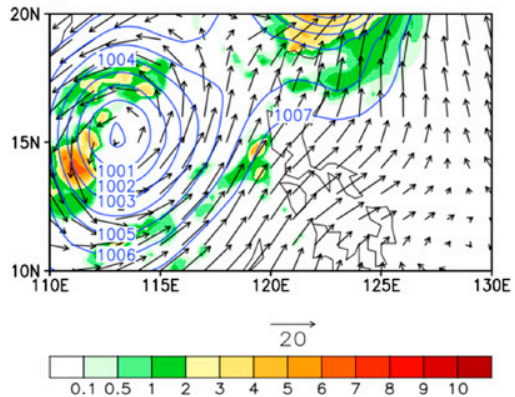

h) OBS(VOR) OOZ 28SEP

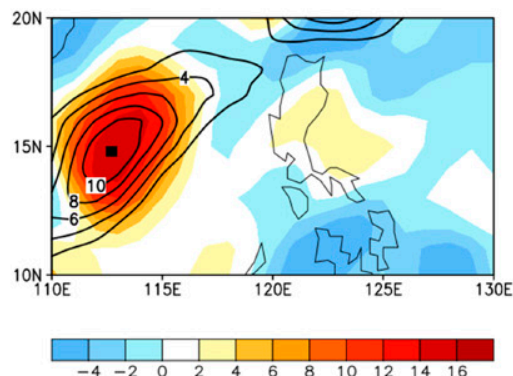

FIG. 4. As in Fig. 2, but at (a)-(d) 0600 UTC 27 Sep and (e)-(h) 0000 UTC 28 Sep. The filled square in $(\mathrm{g})$ and $(\mathrm{h})$ indicates the location where the JTWC best track center is found. 
model (Fig. 2e) are now a single region of aggregated heavy rainfall in the middle of the South China Sea (Fig. 3a). The TMPA rain rates showed an intensifying MCS in the middle of the South China Sea a little farther south than the simulated MCS and another MCS off the northern coast of Luzon (Figs. 3b and 3d). A significant amplification of the midtropospheric vortex ${ }^{4}$ occurred between 1800 UTC 25 September (Fig. 3c) and 0000 UTC 26 September (Fig. 3g) in both the WRF and the NCEP FNL, which may be associated with the evolution of the organized convection (see the detailed description of the hourly convection evolution in section 3b). Although the simulated MCV in Fig. $3 \mathrm{~g}$ is more compact and closer to Luzon in comparison to the NCEP FNL during 25 September (Figs. 2c and 2d), the vortex was organized and intensified into a MCV with more concentrated positive midlevel vorticity and weak low-level vorticity (Figs. $3 \mathrm{~g}$ and $3 \mathrm{~h}$ ).

By 0600 UTC 27 September, the WRF simulation developed a broad low-level circulation with enhanced vorticity and falling sea level pressure below the midlevel circulation (Figs. 4a and 4c), which is consistent with the NCEP FNL (Figs. $4 b$ and $4 d$ ). At the end of the simulation (0000 UTC 28 September), both the mid- and lower tropospheric circulations were further intensified (Fig. 4g) with a lower sea level pressure (Fig. 4e). The MSLP was around $1000 \mathrm{hPa}$, which agrees well with the NCEP FNL (Fig. 4f). According to the RSMC TokyoTyphoon Center, the MSLP was $1000 \mathrm{hPa}$ at both 1800 UTC 27 September and 0000 UTC 28 September. Note that the simulated low-level circulation was more compact and had weaker winds than the circulation in the NCEP FNL, which is on a $1^{\circ} \times 1^{\circ}$ grid. Also, the simulated center location is substantially farther east relative to both the NCEP FNL and the JTWC best track (Fig. 4g). In this CTL simulation (Fig. 4e), strong convective cells were well organized and concentrated near the center of the low pressure system.

Overall, the simulation reasonably represented the convective organization, low-level circulation, and pressure pattern of a tropical depression. In contrast, the NCEP FNL (Fig. 4f) were more representative of a monsoon depression due to the large radius of maximum winds in the NCEP FNL and the distribution of convection with the largest TMPA rain rates occurring away from the core

\footnotetext{
${ }^{4}$ The amplification of the midtropospheric vortex associated with the organization of convection is more pronounced in the WRF Model than in NCEP FNL, although this does not necessarily indicate that the model overemphasizes vorticity enhancement associated with the organization of convection. Comparison of three reanalysis datasets (NCEP FNL, MERRA, and ECMWFYOTC) reveals some uncertainty about whether the NCEP FNL is correct in the mesoscale structure in Figs. 2-4.
}

(Beattie and Elsberry 2013). Finally, the simulated vortex at the TD stage has become much more symmetric and has intensified (Figs. 4e-g), and it is clearly more vertically aligned in contrast to the preformation stage (Figs. 2 and 3).

This TC formation occurs near a strong vertical wind shear zone (Fig. 5). The earlier westward tilt of SYN2 (Fig. 2c) is attributed to large easterly wind shear $\left(>10 \mathrm{~m} \mathrm{~s}^{-1}\right.$ ) (Fig. 5a), which agrees with the NCEP FNL (Fig. 5b). However, a large meridional gradient exists in the shear magnitude (e.g., more unfavorable shear farther south). The MCV intensification was favorably located in a weaker wind shear zone $\left(<10 \mathrm{~m} \mathrm{~s}^{-1}\right.$, latitude of $\sim 16^{\circ} \mathrm{N}$ in Figs. $5 \mathrm{~b}$ and 5f). On 27 September, the strong northeasterly wind shear (Figs. 5c and g) is possibly causing the vortex centers to become misaligned in the vertical (Figs. 4c and 4d) as suggested by Davis and Ahijevych (2012). Given the large wind shear in the environment around the pre-TC circulation, the key questions are how the MCV (SYN2 in Figs. 2 and 3) intensified and transformed into a TD (Fig. 4), and how the land-based convection impacts the MCV and the transition process, which will be explored in section 5 .

\section{b. Evolution of convection}

It is challenging for numerical models to predict the exact location and the intensity of MCSs, while synopticscale TC precursor circulations are typically more predictable (Wang et al. 2010). Consequently, this section will examine whether the CTL experiment properly represents the important features in the observed convective evolution over the ocean and over the land in relation to the MCV organization (section 3a). The TMPA in the morning (at 0000 UTC) of 25 September in Fig. $2 b$ indicates the $\operatorname{MCS}(\mathrm{O})$ was embedded in the monsoon flow, but no convection was occurring directly over Luzon at this time. As in the hourly infrared brightness temperature (BT) images (Fig. 6a), convective activity in the $\operatorname{MCS}(\mathrm{O})$ continued to be active in the afternoon with the cirrus cloud shield extending southwestward due to the reversal of the monsoon flow aloft to northeasterlies. The oceanic convection temporarily weakened from 1600 LT (0800 UTC; Fig. 6b). Meanwhile, localized convective cells $(\mathrm{BT}<200 \mathrm{~K})$ erupted over eastern Luzon. This $\mathrm{MCS}(\mathrm{L})$ was invigorated along the west coast by 2000 LT (Figs. 6c-f) and moved off the west coast of the Philippines at $2100 \mathrm{LT}$ (Fig. 6g). At this time, the ECMWF-YOTC analysis indicates that both $\operatorname{MCS}(\mathrm{O})$ and $\operatorname{MCS}(\mathrm{L})$ separately have intense cyclonic vorticity in their convective cores (VHTs; Figs. 6s and 6t).

The two MCSs are very close together until $2300 \mathrm{LT}$ (Figs. 6h and 6i), when $\mathrm{MCS}(\mathrm{O})$ has been propagated 

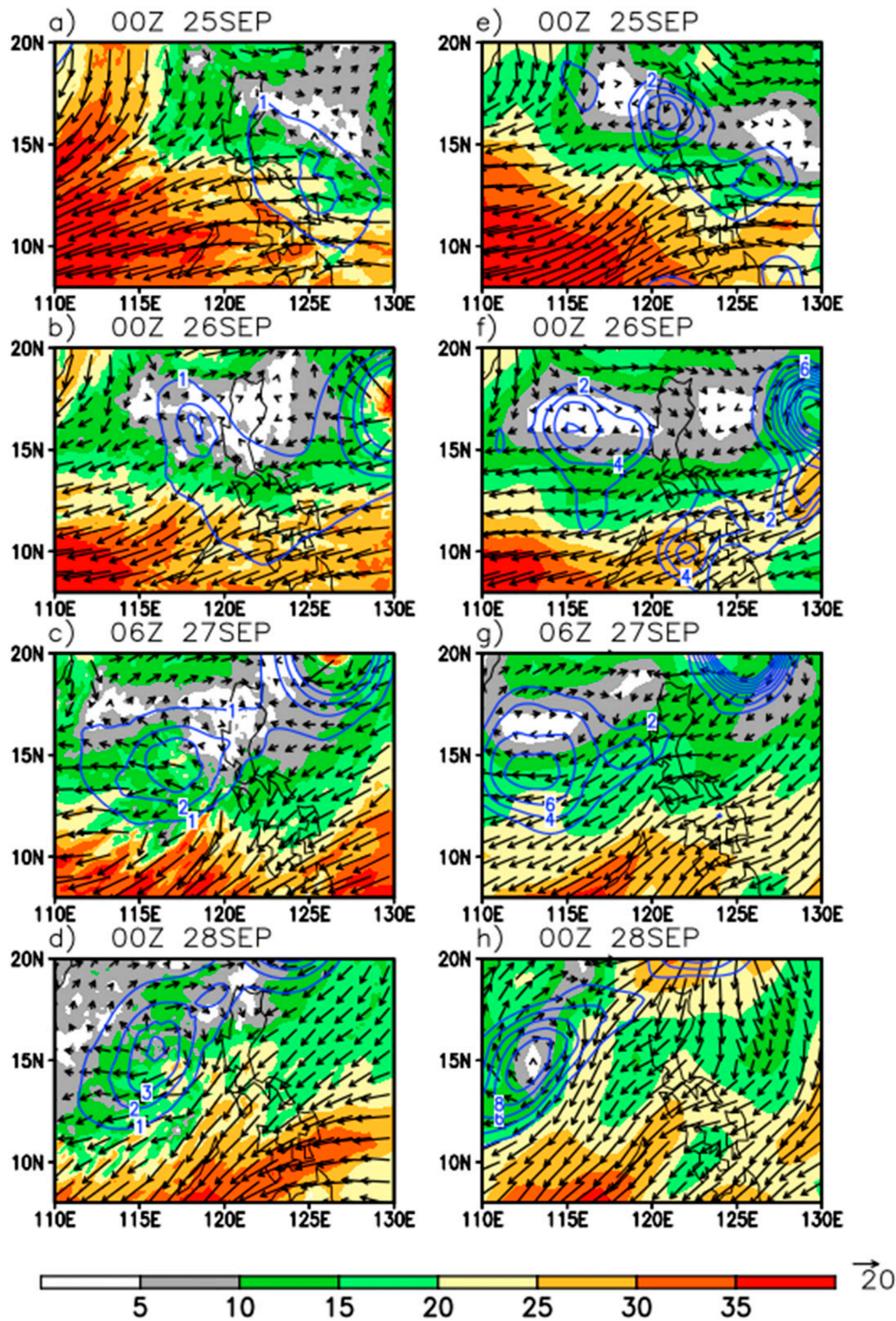

FIG. 5. Vertical wind shear magnitude ( $\mathrm{m} \mathrm{s}^{-1}$, shading scale at bottom) and direction (reference vector at bottom right) between 200 and $850 \mathrm{hPa}$, and the filtered 500-hPa vorticity (blue contour) from (left) WRF Model integration CTL experiment and (right) NCEP FNL: (a),(d) 0000 UTC 25 Sep; (b),(f) 0000 UTC 26 Sep; (c),(g) 0600 UTC 27 Sep; and (d),(h) 0000 UTC 28 Sep, which correspond to the times in Figs. 2a-d, 3e-h, 4a-d, and 4e and 4f, respectively. 

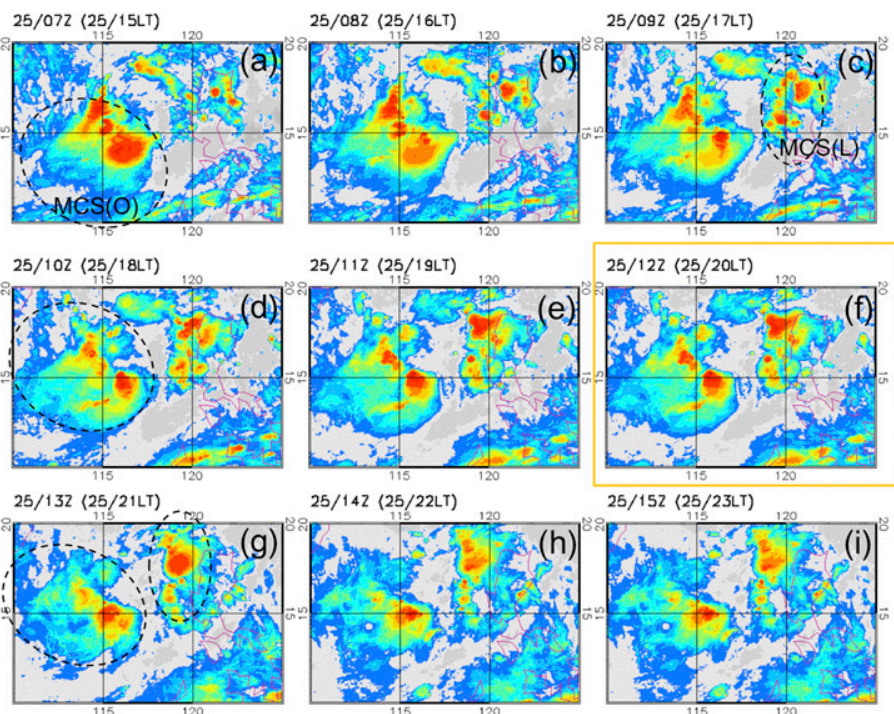

$25 / 142(25 / 22 L T)$
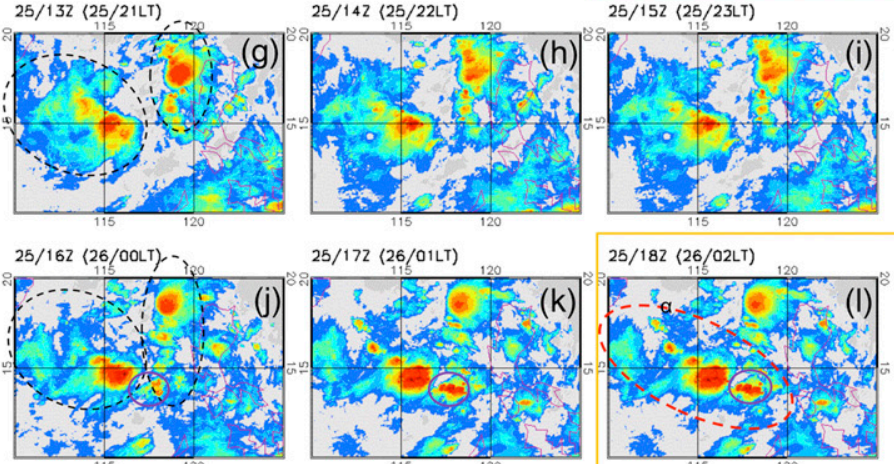

$25 / 172(26 / 01 L T)$

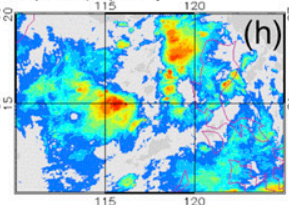

$25 / 192(26 / 03 L T)$
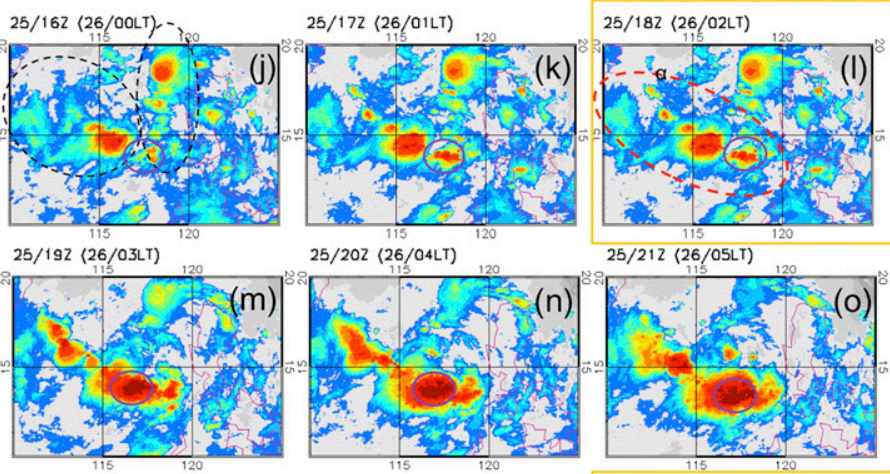

$25 / 202(26 / 04$ LT $)$

$25 / 212(26 / 05 L T)$
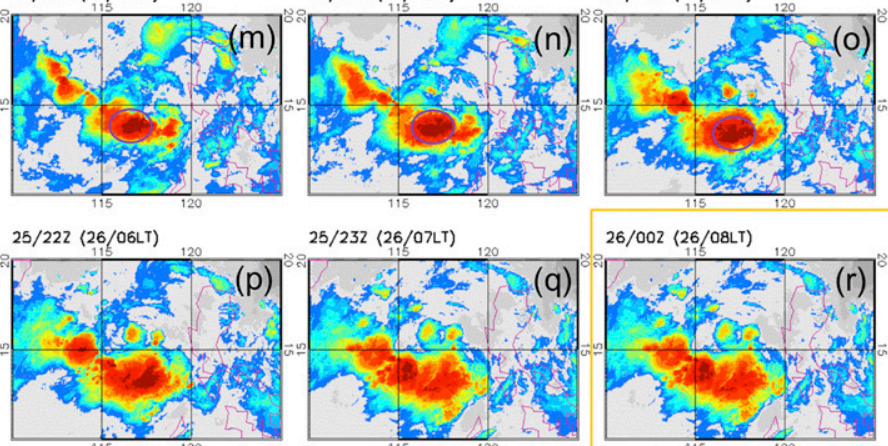

$26 / 002(26 / 08 \mathrm{LL})$

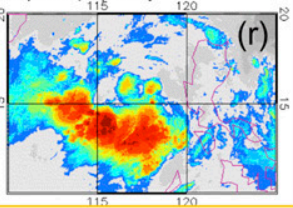

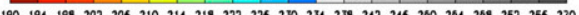

25SEP / $12 Z$

25SEP / $18 Z$

26SEP /OOZ
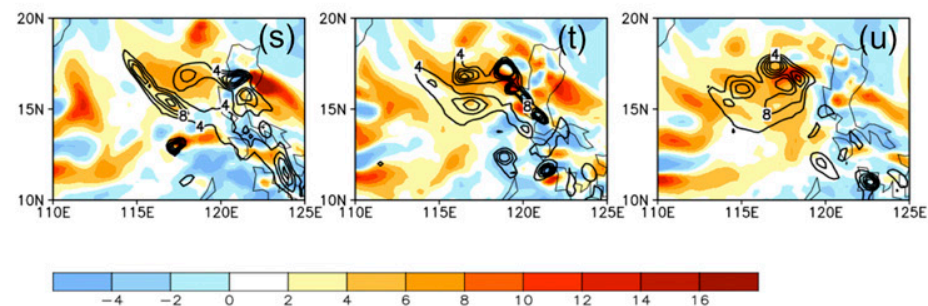

FIG. 6. Hourly images of MTSAT-1R infrared BT (K, color scale below) from (a) 0700 UTC (1500 LT) 25 Sep to (r) 0000 UTC (0800 LT) 26 Sep. The 6-hourly distributions of ECMWF-YOTC vorticity $\left(10^{-5} \mathrm{~s}^{-1}\right)$ at 850 (shading, scale below) and $500 \mathrm{hPa}$ (contours) in (s)-(u) correspond with (f),(1), and (r) with a yellow box, respectively. The MCS(O) and the MCS $(\mathrm{L})$ are indicated as the black dashed circles, and the new convective cells between the two convective systems are indicated by the purple circles in (j). The organized cloud cluster, that was developing associated with activation of the cold-topped convective cells between $\operatorname{MCS}(\mathrm{O})$ and $\operatorname{MCS}(\mathrm{L})$, is indicated as $\alpha$ as in Fig. 3b. 


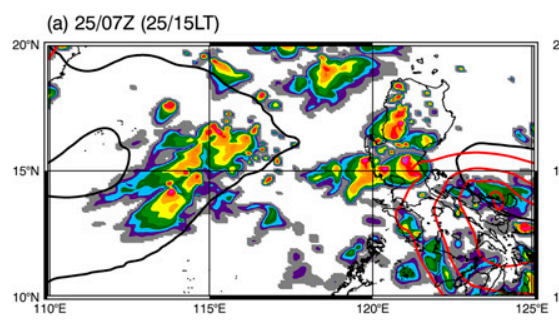

(d) $25 / 16 Z(26 / 00 L T)$

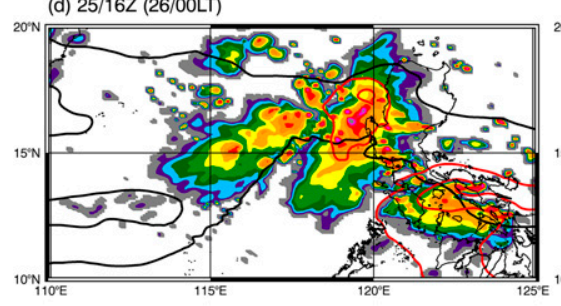

(e) $25 / 19 Z(26 / 03 L T)$

(b) $25 / 10 Z(25 / 18 L T)$
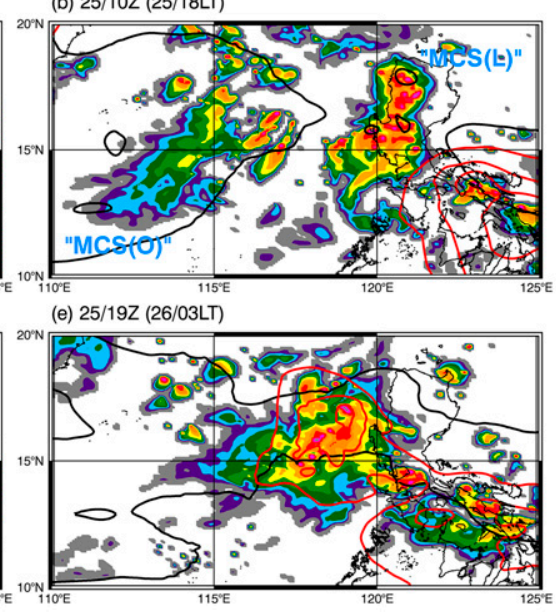

(f) $25 / 22 Z(26 / 06 L T)$
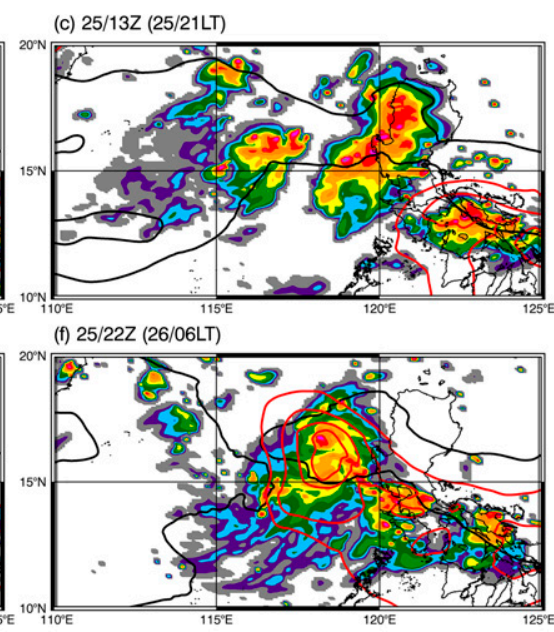

FIG. 7. Simulated maximum radar reflectivity (shading) and filtered vorticity $\left(10^{-5} \mathrm{~s}^{-1}\right)$ at 850 (black contours at $\left.1.0 \mathrm{value}\right)$ and $500 \mathrm{hPa}$ (red contours at 1.0, 1.5, 2.0, 2.5 values) in the CTL experiment at times corresponding to the six left panels in Fig. 6.

eastward by the southwesterly monsoon flow while $\mathrm{MCS}(\mathrm{L})$ has propagated westward at the leading edge of the elongated pre-Mekkhala circulation (SYN2). At 0000 LT 26 September, cold-topped convective cells (purple circle in Fig. 6j) began to form ahead of the leading edge of the westward-propagating $\mathrm{MCS}(\mathrm{L})$ in a region to the east of the eastward-propagating $\mathrm{MCS}(\mathrm{O})$ (Figs. 6k and 61). These convective cells with mesoscale cyclonic circulation (Fig. 6t) rapidly developed into an organized cloud cluster with very cold $(<194 \mathrm{~K})$ cloud tops (Figs. 6m-o), and the residual MCS(L) transformed into a trailing rainband that constituted the northern portion of the cyclonic circulation (Fig. 6t). This cloud cluster (Figs. 6p-r) continued to remain convectively active and elongated due to the new convection approaching from the west. As a result of this rapid development of the convective cells between MCS(L) and $\operatorname{MCS}(\mathrm{O})$, the cloud cluster at 0800 LT 26 September (Fig. 6r) was embedded in the well-organized midtropospheric MCV (Figs. 6u and 3h) that later developed into the pre-Mekkhala tropical depression.

The simulated maximum radar reflectivity (over all levels) in Fig. 7a demonstrates that the CTL simulated the MCS(O) associated with the monsoon at $0700 \mathrm{UTC}$ 25 September reasonably well (cf. Fig. 6a). Three hours later at 1000 UTC (1800 LT; Fig. 7b), an extensive area of simulated radar reflectivity corresponding to $\operatorname{MCS}(\mathrm{O})$ in Fig. 6d developed over the South China Sea, and vigorous convection within MCS(L) was simulated over Luzon. At $2100 \mathrm{LT}$ (Fig. 7c) in the simulation, the MCS(O) has translated closer to the MCS(L) over Luzon, and when MCS(L) moves offshore at $0000 \mathrm{LT}$ (Fig. 7d) it interacts more directly with the oceanic $\operatorname{MCS}(\mathrm{O})$. Consequently, the two systems combine rapidly by 0300 LT (Fig. 7e), which is similar to the observations, although displaced somewhat to the north in the simulation.

The evolution of the MCV from the simulated convective cells during the interaction of the two MCSs is shown in Fig. 7e. The spinup of the simulated midlevel circulation occurs more rapidly and closer to Luzon (Figs. 3c and 7f) than was observed (Fig. 3d). However, the key features of a land-based MCS moving offshore and interacting with a preexisting oceanic MCS agree reasonably well with the observed sequence of events.

\section{Role of land on TC formation: Sensitivity tests}

\section{a. Hypothesis}

The central hypothesis of this study is that landbased convection over Luzon played a critical role in the pre-Mekkhala depression development, which is possibly a necessary condition for this TC formation The null hypothesis would be that MCS(L) plays only a minor role in TC formation, and thus the favorable synoptic conditions and oceanic MCS alone are sufficient for development.

\section{b. Evolution of convection in no-land setting}

In general, the diurnal peak of convection and precipitation is in the afternoon to evening over the tropical land, as shown in the evolution of MCS(L) in Fig. 7. Over the open ocean, convection is generally suppressed around that time (Yang and Smith 2006). Oceanic convection is more enhanced during the late night to early morning due to enhanced nocturnal radiative cooling that destabilizes the upper layer of the cloud (Tao et al. 1996). In this study, 


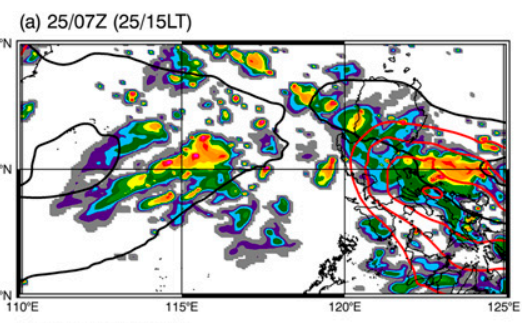

(d) $25 / 16 Z(26 / 00 L T)$
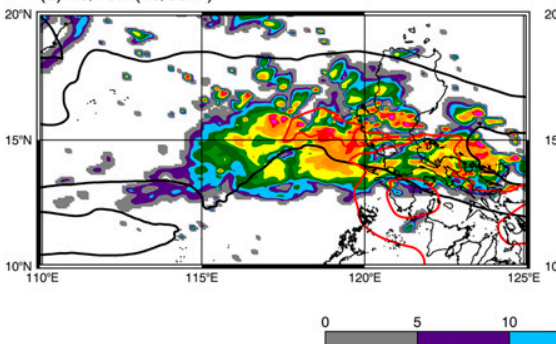

(b) $25 / 10 Z(25 / 18 L T)$

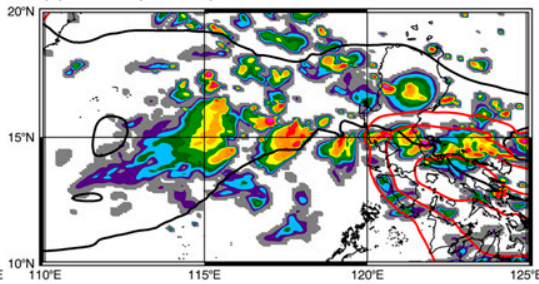

(e) $25 / 19 Z(26 / 03 L T)$
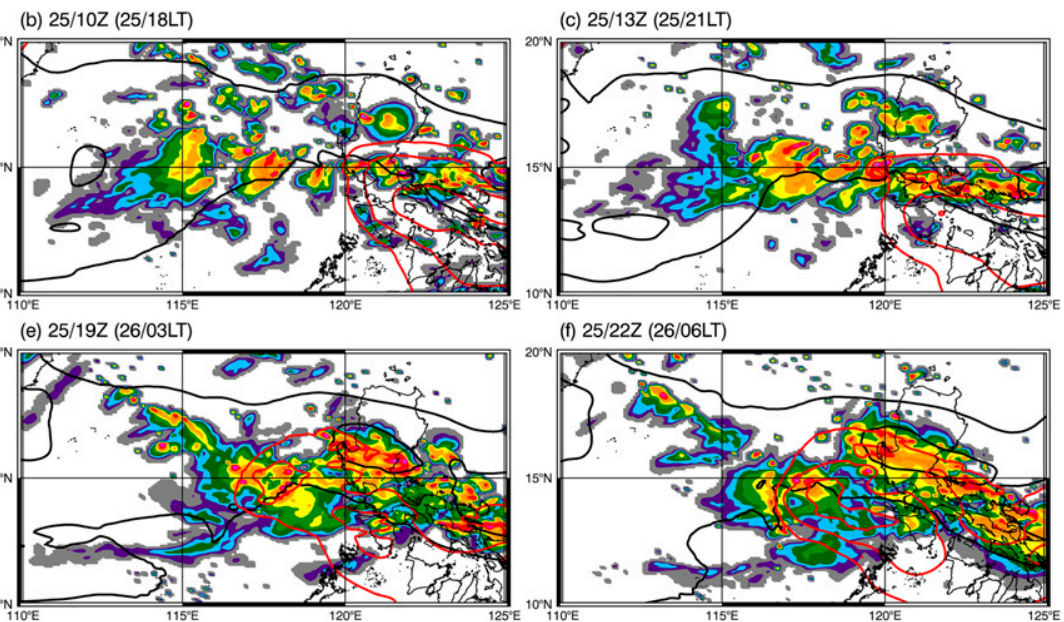

(f) $25 / 22 Z(26 / 06 L T)$
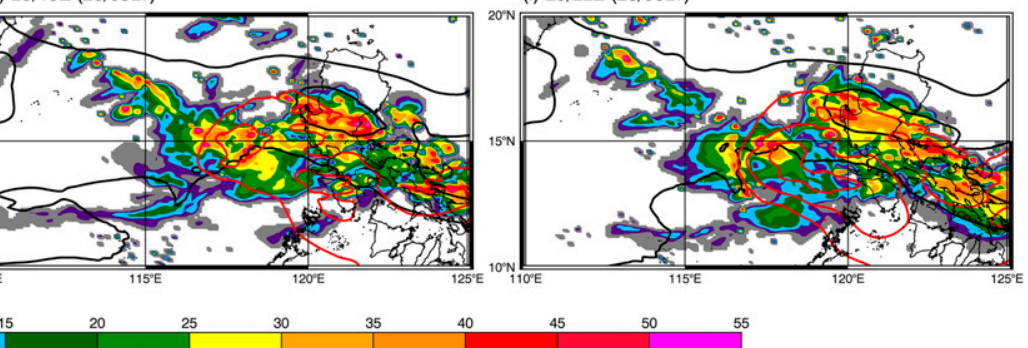

FIG. 8. As in Fig. 7, but for the NoL experiment corresponding to the CTL experiment (Table 1).

the no-land experiment considers the South China Sea as an open ocean connected to the Philippine Sea (Fig. 1). Thus, the first step is to verify that the removal of the northern Philippine Islands properly suppresses the afternoon land-based convection.

Three-hourly variations of simulated maximum reflectivity from 0700 UTC (1500 LT) to 2200 UTC 25 September (0600 LT 26 September) obtained from the no-land (NoL) experiment (Table 1) are shown in Fig. 8. At 0700 UTC (Fig. 8a), the NoL experiment reasonably replicates the $\operatorname{MCS}(\mathrm{O})$ that is embedded in the monsoon. Another oceanic convective region forms over the Philippine Sea near $125^{\circ} \mathrm{E}$ in conjunction with the pre-Mekkhala synoptic circulation. However, the convection originating over the Philippine Islands was not simulated in the NoL experiment (Figs. $8 \mathrm{~b}$ and $8 \mathrm{c}$ ) since the land surface heating and the differential heating between the sea and the Philippines responsible for the sea-breeze circulation were not included. Instead, only scattered convection was simulated in the evening over the virtual sea area in the late afternoon (Fig. 8b).

The temporal evolution of the $\operatorname{MCS}(\mathrm{O})$ from the afternoon through the evening ( $2100 \mathrm{LT})$ is quite similar between the CTL (Fig. 7c) and the NoL (Fig. 8c) experiments. That is, the $\operatorname{MCS}(\mathrm{O})$ originates in the southwest monsoon flow in both experiments, with new convective cells forming downstream (eastward) of the prior convective area. Oceanic nocturnal convection maxima were simulated in both the $\operatorname{MCS}(\mathrm{O})$ near $15^{\circ} \mathrm{N}$, $117^{\circ} \mathrm{E}$ and in the northwest quadrant of the synoptic circulation in the Philippine Sea (Fig. 8e). However, instead of interacting with the land-based convection to form the pre-Mekkhala circulation as in the CTL
(Fig. 7f), the simulated $\mathrm{MCS}(\mathrm{O})$ in the NoL experiment became part of a large convective cluster with maximum $500-\mathrm{hPa}$ vorticity near $13^{\circ} \mathrm{N}, 119^{\circ} \mathrm{E}$ at $0600 \mathrm{LT} 26 \mathrm{Sep}-$ tember (Fig. 8e).

In summary, the no-land experiment demonstrates that the land-based convection was properly inhibited, allowing for an investigation of whether the development and movement offshore of the Philippine landbased convection have positive contributions to the pre-Mekkhala depression formation. The role of the $\operatorname{MCS}(\mathrm{O})$ is somewhat different in the NoL experiment. This convective area propagated eastward in the monsoon flow and restrengthened south of $15^{\circ} \mathrm{N}$ through the interaction with the approaching synoptic circulation over the Philippine Sea. To test the central hypothesis, we further examine the sea level pressure evolution following the MCV to determine whether MCS(L) was critical or whether the broadly distributed oceanic convection was sufficient for the TC formation.

\section{c. MSLP evolutions}

The temporal variations of MSLP within a $2^{\circ}$ radius relative to the midtropospheric vortex center are presented in Fig. 9. Because of the elongated precursor synoptic circulation during the earlier stage, the center can be well defined only after the end of 25 September. The MSLP center became better defined in both the control and the no-land experiments when the MCV developed in association with the deep convection at 2200 UTC 25 September (Figs. 7f and 8f, respectively). Note this midtropospheric mesoscale circulation evolved near the leading edge of the approaching, synoptic circulation (SYN2), although the placement of the MCV 

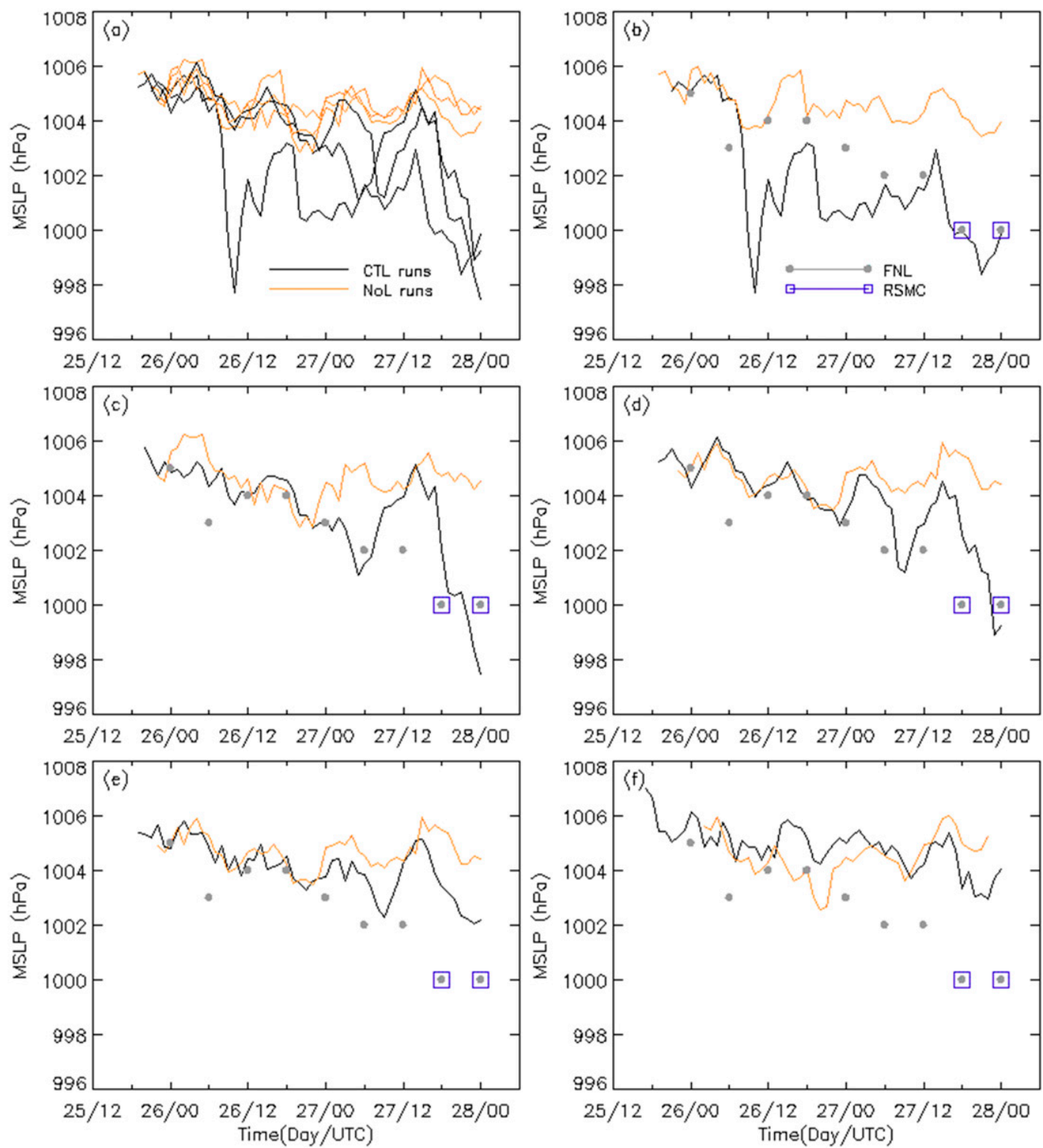

FIG. 9. Temporal variation of MSLP within $2^{\circ}$ from the center of the pre-Mekkhala midlevel vortex center for selected WRF experiments in Table 1: (a) CTL, CTL150, and CTL300 (black lines) vs NoL, NoL150, and NoL300 (scarlet lines); (b) CTL vs NoL; (c) CTL150 vs NoL150; (d) CTL300 vs NoL300; (e) CTL200 vs NoL200; and (f) CTL250 vs NoL250, which are all overlaid with NCEP FNL (gray-filled circle) and RSMC Tokyo best track (blue square) values.

depends on the presence of the land-based convection in the WRF sensitivity tests (to be discussed later).

The MSLP evolutions from the no-land experiments are shown in Fig. 9a overlaid with the three control-land experiments from Table 1 that developed the circulation. All five sensitivity tests are individually compared in Figs. 9b-f with the comparison for two underdeveloped control-land versus no-land experiments in Figs. 9e-f. First note that all three of the no-land experiments (Fig. 9a, scarlet lines) have a similar MSLP tendency of a small $(\sim 2 \mathrm{hPa})$ decrease over the 2.5-day period with a superposed semidiurnal oscillation. In contrast, each of the control-land experiments (black lines) intensifies the system and simulates an MSLP of $\sim 999 \mathrm{hPa}$ at 0000 UTC 28 September.

The difference in MSLP evolutions is most evident for the NoL and CTL experiments (Fig. 9b). The CTL has a rapid decrease in MSLP to $998 \mathrm{hPa}$ by $0900 \mathrm{UTC}$ 26 September, which may be partly attributed to the diurnal extension of the monsoon vortex under the MCV (more details in section 5c). After some filling by 1800 UTC 26 September, the MSLP in the CTL oscillates 
between 1001 and $1003 \mathrm{hPa}$ until deepening occurs around 1200 UTC 27 September, resulting in an MSLP near $1000 \mathrm{hPa}$ similar to that reported by RSMC Tokyo. Therefore, the CTL is listed in Table 1 as a "developing", storm. Although the NoL experiment has an early decrease in MSLP to $1004 \mathrm{hPa}$ by 0600 UTC 26 September similar to the NCEP FNL, the MSLP then fluctuates around this value for the remainder of the simulation, which is considered to be "no development."

The CTL150 (Fig. 9c) better matches the steady deepening trend of the NCEP FNL through 0600 UTC 27 September, although the semidiurnal perturbation is more prominent. Although the MSLP sharply increases for $6 \mathrm{~h}$, it then decreases about $7 \mathrm{hPa}$ in about $9 \mathrm{~h}$, which qualifies it as developing. Despite the steady deepening of the NoL150 until 1800 UTC 26 September, filling occurred after this time and the simulation was designated as no development.

The intercomparison between CTL300 and NoL300 (Fig. 9d) is similar to the previous experiment in that the CTL300 also has a steady downward trend in MSLP similar to the NCEP FNL, but it does not have the sharp deepening and filling as in the CTL. In addition, the CTL300 has a pronounced semidiurnal pressure oscillation that appears reasonable, and this simulation has an MSLP at 0000 UTC 28 September that matches well with the RSMC Tokyo estimate of $1000 \mathrm{hPa}$. Consequently, it is concluded that the CTL300 experiment has a good performance as a developing simulation.

Further evidence of the sensitivity of the WRF simulations to the convective organization is indicated by the intercomparisons between CTL200 versus NoL200 in Fig. 9e and CTL250 versus NoL250 in Fig. 9f. The MSLP deepening of the low-level circulation is underestimated in the two control experiments and thus are labeled as under development compared to the RSMC Tokyo MSLP estimate. Both NoL200 and NoL250 do not simulate continuous SLP deepening and do not have a low-level circulation at the end of the integration and thus are designated as no development.

Accordingly, convection that is forced to be "oceanic" or "continental" in the WRF microphysics scheme $N_{c}$ setting does not appear to systematically alter the development of TC, whereas consistent control-land versus no-land differences do indeed point to the land-based convection as a facilitator for development. In no case did a simulation develop without land, so the primary hypothesis is well supported.

\section{Impacts of land-based convection on near-coastal TC formation process}

This section further investigates the process by which the land-based convection contributes to TC development. The simulated mesoscale interaction and the subsequent evolution together with those from the TMPA and NCEP FNL are shown in the time-versus-longitude diagrams in Fig. 10.

As in the NCEP FNL (Fig. 10h), the monsoon precursor vortex (red arrow, Fig. 10c) in the CTL gradually extends eastward toward the Philippines over the 3 days. Diurnal perturbations in the monsoon flow are simulated every day with maximum speeds around 0500-0700 UTC (afternoon 1300-1500 LT) and an eastward expansion until around 1600 UTC (0000 LT), which is consistent with other recent studies (Huang et al. 2010; Park et al. 2011). Park et al. (2011) showed that increased differential cooling between the Asian continent to the west and the surrounding sea in the early morning induces increased large-scale westerlies over the South China Sea that may promote oceanic convective updrafts.

While $\operatorname{MCS}(\mathrm{O})$ (white dashed ellipse in Fig. 10b) originated over the western South China Sea in a region of higher surface $(2 \mathrm{~m})$ air temperatures (Fig. 10a), it propagates eastward toward Luzon (Fig. 10b), where the low-level monsoon precursor circulation is also extended diurnally (Figs. 6 and 10c). The local vorticity associated with $\operatorname{MCS}(\mathrm{O})$ is embedded in the monsoon circulation, and the vorticity enhancement can contribute to TC spinup.

Accordingly, this TC formation can be regarded as a two-stage process (Fig. 10c). The first stage (25 September) consists of preconditioning and the formation of the MCV. The second phase (26 and 27 September) is characterized by low-level circulation development in cooperation with the monsoon vortex.

\section{a. Stage 1: Formation of the midtropospheric MCV}

The elongated, tilted precursor circulation (SYN2 in Fig. 2c) was moving westward from the Philippine Sea (blue arrow in Fig. 10c), which is in agreement with the NCEP FNL (Fig. 10h). At the leading edge of the synoptic disturbance, 2-m temperature increases (Fig. 10a) were simulated from the afternoon through evening between $120^{\circ}$ and $122^{\circ} \mathrm{E}$. The two temperature maxima over land are attributed to the enhanced surface heating over two mountain ranges in the Philippines (Fig. 1b). The differential solar heating across the land-sea boundary and inland surface thermal boundaries between higher and lower topography (Fig. 10a) produced low-level convergence and convective lifting (Yang and Smith 2006), which facilitated intense convection over the Philippines (Figs. 7a-d). Accordingly, the CTL experiment simulates the $\mathrm{MCS}(\mathrm{O})$ development on the cyclonic shear (northern) side of the $850-\mathrm{hPa}$ relative vorticity maximum, and the vigorous $\mathrm{MCS}(\mathrm{L})$ was on the leading edge of the elongated circulation (Fig. 10c). As indicated above, the interaction between the $\operatorname{MCS}(\mathrm{O})$ and $\mathrm{MCS}(\mathrm{L})$ resulted in a persistent, well-defined MCV offshore of 
(a) 2 M TEMP

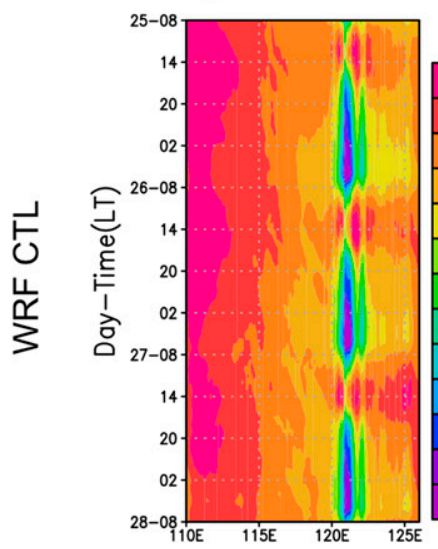

(d) $2 \mathrm{M}$ TEMP

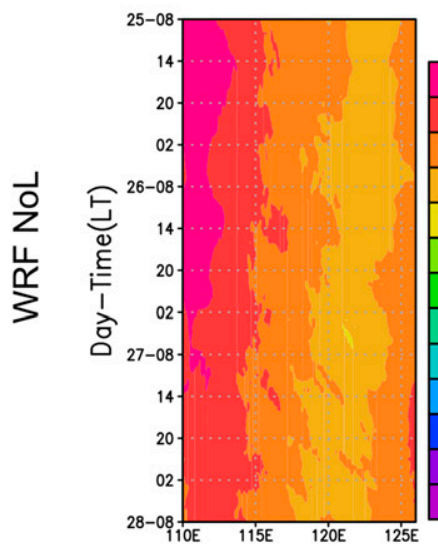

(b) Max_dbz

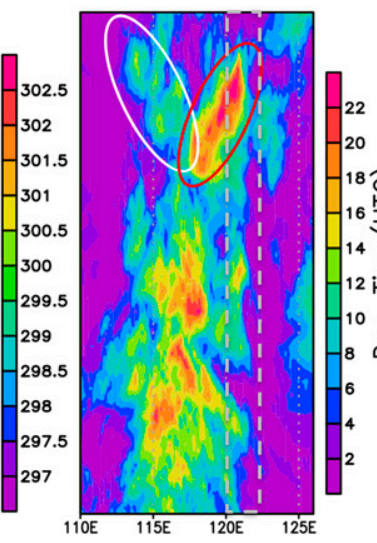

(e) Max_dbz

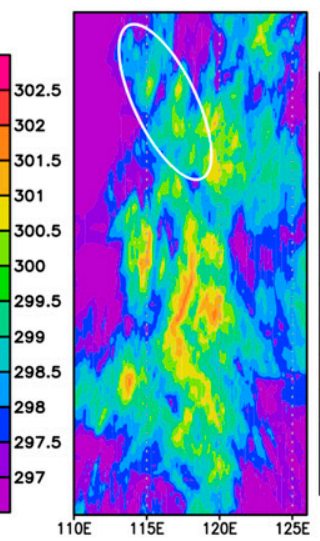

(g) TRMM 3842 rain

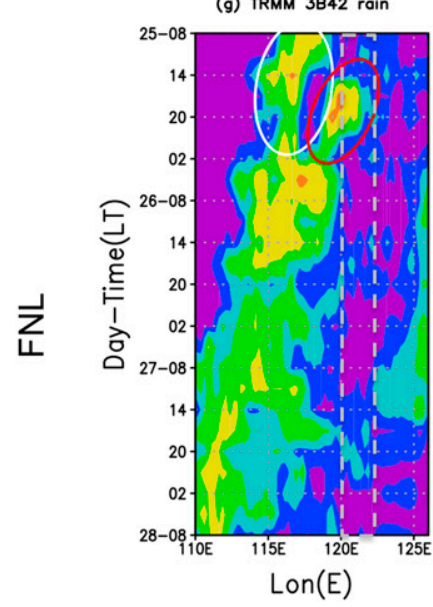

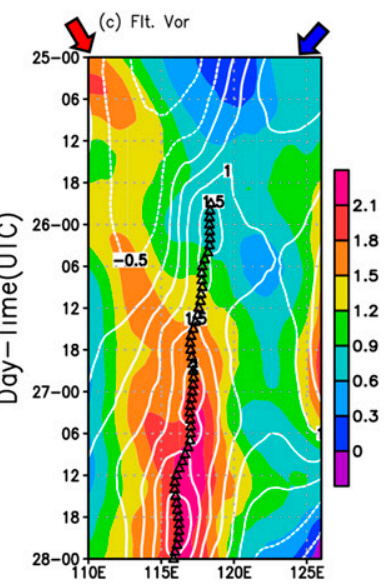
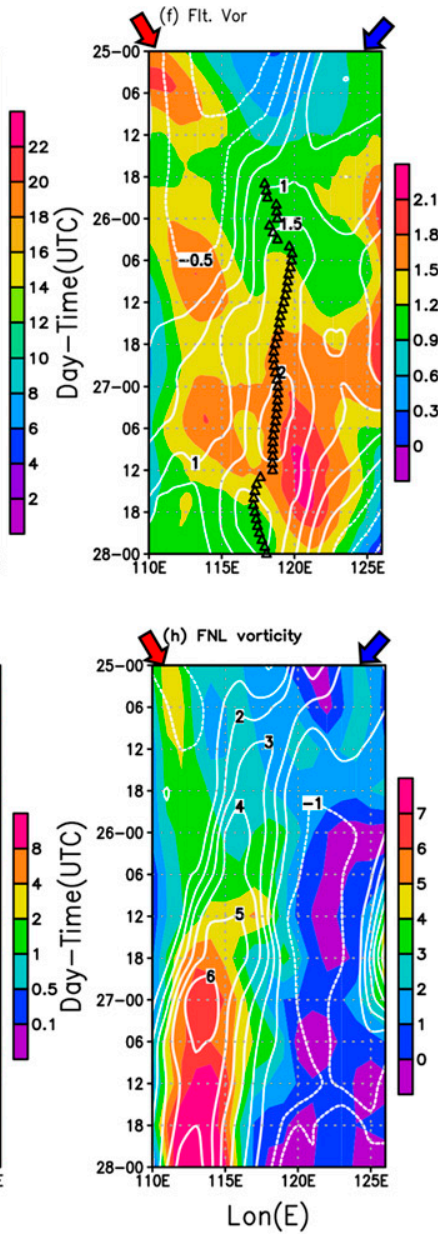

FIG. 10. Hovmöller time-longitude diagrams for the CTL experiment of (a) 2-m air temperature ( $\mathrm{K}$, scale on right, ordinate in local time), (b) maximum reflectivity ( $\mathrm{dB} Z$, scale on right), and (c) filtered vorticity $\left(10^{-5} \mathrm{~s}^{-1}\right.$, scale on right, ordinate in universal time) at 850 (shading) and $500 \mathrm{hPa}$ (contours) averaged over $11^{\circ}-19^{\circ} \mathrm{N}$. (d)-(f) As in (a)-(c), but for the NoL experiment. The Hovmöller diagram of (g) TRMM 3B42 rain rate $\left(\mathrm{mm} \mathrm{h}^{-1}\right.$, scale on right, ordinate in local time) and (h) FNL vorticity $\left(10^{-5} \mathrm{~s}^{-1}\right.$, scale on right, ordinate in UTC) at 850 (shading) and $500 \mathrm{hPa}$ (contours) averaged over $11^{\circ}-19^{\circ} \mathrm{N}$. The white ellipse indicates the $\mathrm{MCS}(\mathrm{O})$; the red ellipse is the MCS (L) originated from the Philippines land area (gray dashed line). The small black triangles in (c) and (g) are the pathways of the midlevel MCVs. Two primary synoptic precursors are shown: SYN1 (red arrows) and SYN2 (blue arrows; see Fig. 2c). 
Luzon (black triangles in Fig. 10c). Although the translation direction of the oceanic convection is different from the TMPA, other major vortex evolutions in the CTL (e.g., MCV evolution after the merger of the two MCSs) are similar to the observations (Figs. 10g and 10h).

In contrast, the differential surface heating is mostly absent in NoL simulations (Fig. 10d), which explains why the intense land convection did not evolve (Figs. 8a-d). Whereas the two primary synoptic conditions and the MCS $(\mathrm{O})$ are well simulated in the NoL experiments (Fig. 10e), what is different is the absence of an interaction with the strong convection developing over Luzon. Instead, abundant oceanic convection evolves in the westward-moving, elongated disturbance (Fig. 10e). Note that the filtered midlevel vortex center was also developed within the $\mathrm{MCS}(\mathrm{O})$ at the end of 25 September (Fig. 8f). However, the midtropospheric vorticity (Fig. 10f) in NoL simulations associated with the broadly distributed oceanic convection was more loosely organized to the east than that of CTL simulations (Fig. 8f).

Figure 11 shows vertical cross sections through the primary convective regions in the CTL and NoL simulations for more detailed structures of the convection and dynamics. The MCS $(\mathrm{O})$ is significantly tilted westward in the vertical in CTL and NoL simulations due to the lowlevel monsoon westerly and the upper-level easterly background flow (gray contour in Figs. 11a and 11g). New convective cells with positive vorticity anomalies develop to the east of the older convective regions (Figs. 11c and 11d). The convective updraft in the MCS(L) is very intense with maximum cyclonic vorticity in the lower troposphere and new convective cells with positive vorticity anomalies developing to the west (Fig. 11c). The simulated $20-\mathrm{dBZ}$ maximum echo in MCS(L) is found at a higher altitude, which indicates the production of large graupel particles in the stronger updrafts and more concentrated latent heating (not shown). This simulated reflectivity feature is consistent with the Heymsfield et al. (2010) analyses of the NASA Doppler radar observations of land-based convection indicating higher reflectivities and wider convective cores than for oceanic convection.

As the MCS $(\mathrm{L})$ moves offshore close to the $\operatorname{MCS}(\mathrm{O})$ during the nighttime (Figs. 11c and 11d), the local environment has been preconditioned with multiple small-scale low-level vorticity anomalies. It is notable that strong positive vorticity is concentrated over a deep layer (from low to upper troposphere) through vortex stretching associated with the intense convective cells. As seen in Fig. 11d, the new convective cells are simulated in front of the leading edges of the two approaching MCSs (as in the purple circle in the IR images in Figs. 6j-1), and this is the region where the smaller vortices merge into a larger-scale vortex (Fig. 11f). Concentrated local vortices between $118^{\circ}$ and $119^{\circ} \mathrm{E}$ in Fig. $11 \mathrm{f}$ are embedded in the midlevel MCV and contribute to the filtered vorticity maxima in Figs. $7 \mathrm{f}$ and $3 \mathrm{~g}$.

While the westward-tilted $\operatorname{MCS}(\mathrm{O})$ had a similar structure in the NoL simulation during the morning of 25 September (Figs. 11g-i), only a scattered distribution of local vortices was simulated east of $120^{\circ} \mathrm{E}$ in association with the broadly distributed oceanic convection (Figs. 8b-d). Although the leading edge of the MCS(O) was moving eastward in NoL (Figs. 11g-j) as in CTL, the $\operatorname{MCS}(\mathrm{O})$ neither intensified nor produced strong lowlevel vorticity anomalies in the absence of the westwardmoving land-based MCS. Accordingly, local positive vorticity patches are loosely organized (Fig. 111) in NoL (Fig. 8f). Some new oceanic convection developed east of $120^{\circ} \mathrm{E}$ during the early morning of 26 September (Figs. $11 \mathrm{k}$ and 111), but it was not located close enough to MCS(O) to contribute to larger vortex aggregation at that time.

The comparison of the CTL and NoL simulations indicate that the land effects during the first phase of TC formation contribute to a stronger, better-organized vortex in the low to midtroposphere. The land-based convection generated multiple VHTs that merged on a larger scale in cooperation with the monsoon convection. Regardless of the origin of the convection (whether it is from ocean or land), stronger convection with local cyclonic vorticity enhancement (e.g., VHTs) is favorable for TC formation (Hendricks et al. 2004). The positive effect of the land-based convection on TC formation is physically and dynamically reasonable since MCSs over land are fundamentally more intense and deep than oceanic MCSs (Mohr and Zipser 1996).

\section{b. Stage 2: Low-level circulation development by interaction with monsoon}

After the land-based and oceanic MCS interaction, the previous observational study by Park et al. (2015) showed that in the following 2 days, the resulting convective cluster diurnally interacted with another MCS in the monsoon circulation to finally develop into a TC. The Hovmöller diagrams from the simulations show that the low-level monsoon vortex in CTL eventually merged with the midlevel MCV (Fig. 10c) associated with $\operatorname{MCS}(\mathrm{L})$ but that it remained separate when land was removed and MCS(L) did not exist (Fig. 10g).

Here, we further examine the processes for how the midlevel vortex interacted with the monsoon, leading to the development or nondevelopment of TC low-level circulation. The distribution of $850-\mathrm{hPa}$ positive vorticity (shading), 500-hPa MCV (black contours with a blue dot in the center), and mesoscale to synoptic-scale filtered vorticity at the 850 -hPa level (red contours) are shown (Fig. 12). The mesoscale to synoptic-scale vortices 

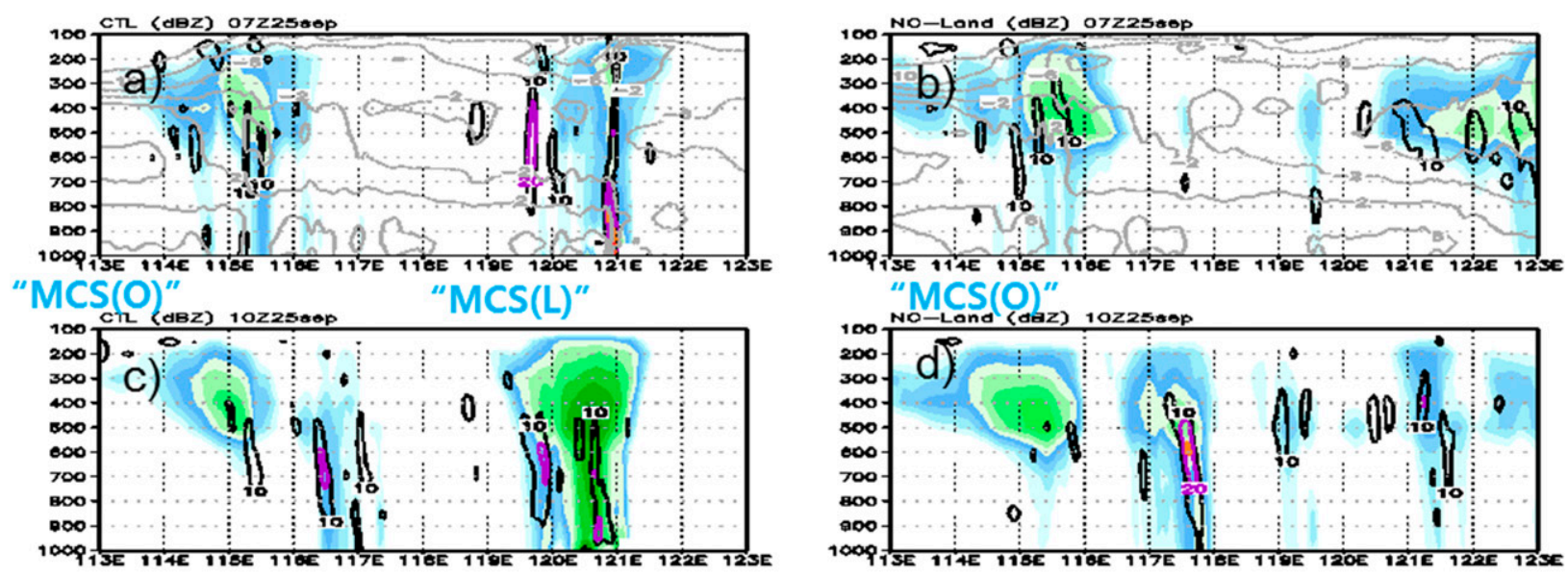

"MCS $($ Q (daz) 10z2saop
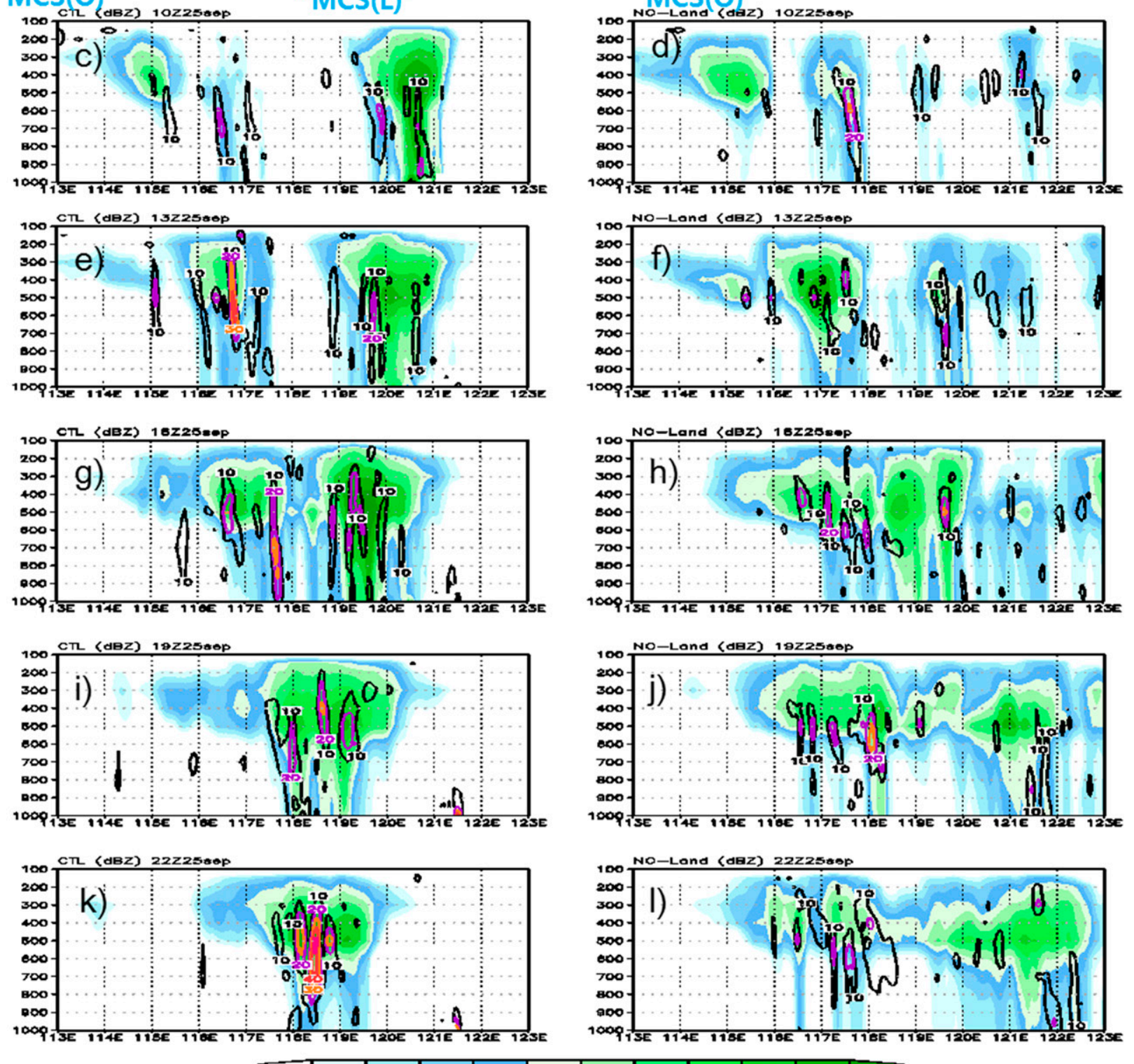

FIG. 11. Three-hourly evolution of vertical cross sections of reflectivities (dBZ, shading) and strong positive vorticity (10, 20, 30, and $40 \times 10^{-5} \mathrm{~s}^{-1}$ with black, purple, scarlet, and red contours, respectively) in the CTL experiment (Fig. 7) along latitudes $15^{\circ}-17^{\circ} \mathrm{N}$ from (a) 0700 to (f) 2200 UTC 25 Sep. Similar vertical cross sections in NoL experiment (Fig. 8) along latitudes $14^{\circ}-16^{\circ} \mathrm{N}$ from (g) 0700 to (1) 2200 UTC 25 Sep. The cross section of zonal winds (gray contours) is shown in the uppermost panels.

include both the TC-induced mesoscale vortex and the synoptic-scale monsoon vortex. In the morning of 26 September (Fig. 12a), the monsoon vortex from the west was far removed from the MCV. Continued convection in the afternoon (Fig. 12b) was followed by the next diurnal maximum of oceanic convection in the early morning (0000 UTC 27 September), which further amplified both the 850- and 500-hPa vorticity of 
(a) 00Z 26SEP

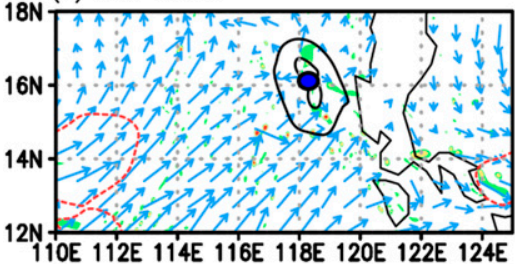

(b) $12 Z 26 \mathrm{SEP}$

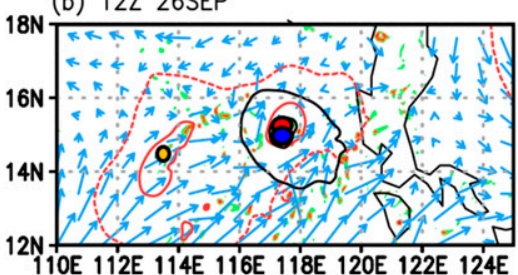

(c) $00 \mathrm{Z} 27 \mathrm{SEP}$

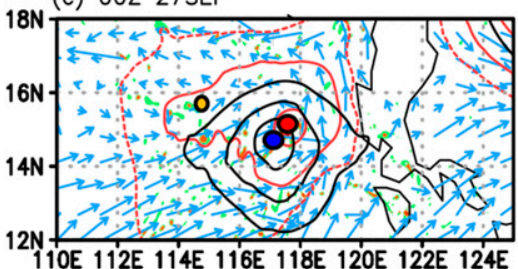
(d) $12 Z 27 \mathrm{SEP}$

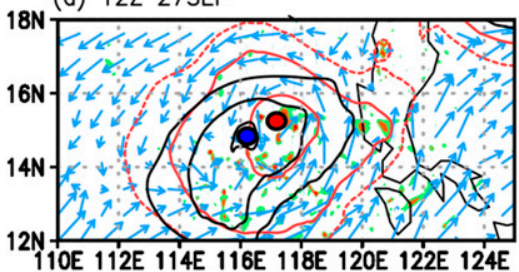
(e) $00 Z$ 28SEP

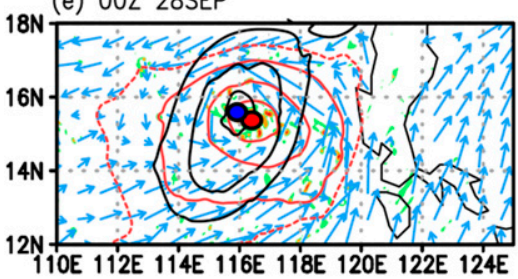

20

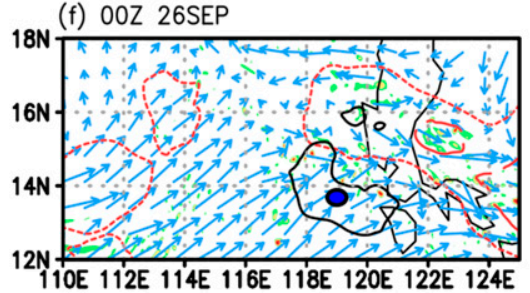

(g) $12 Z$ 26SEP

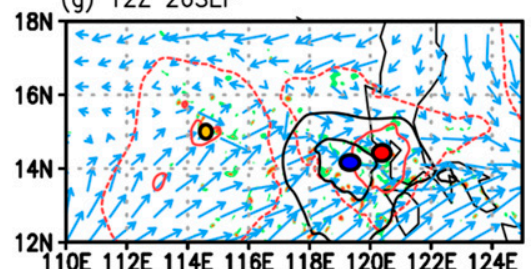

110E 112E 114E 116E 118E 120E 122E 124E

(h) $00 Z$ 27SEP

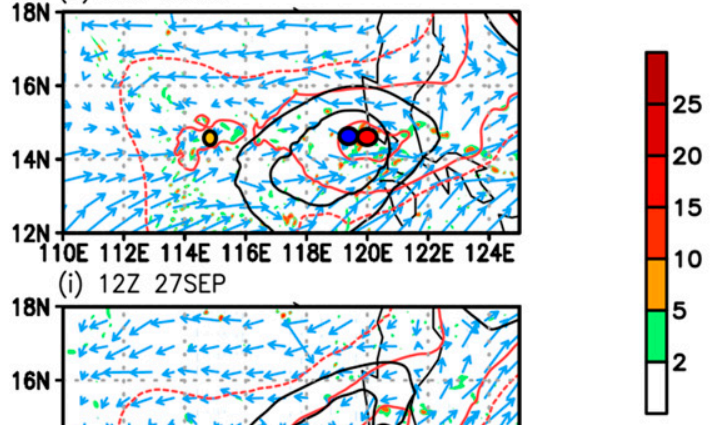

$4 \mathrm{~N}$

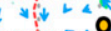

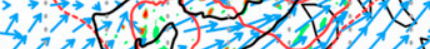

12N $110 \mathrm{E} 112 \mathrm{E} 114 \mathrm{E} 116 \mathrm{E} 118 \mathrm{E} 120 \mathrm{E} 122 \mathrm{E} 124 \mathrm{E}$ (j) $00 Z$ 28SEP

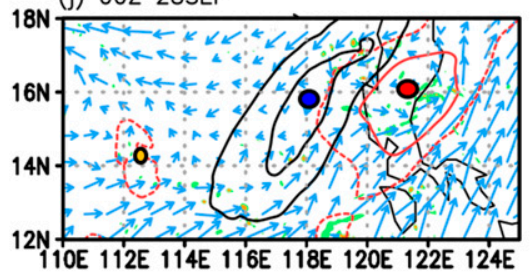

- Pre-TC MCV center

- Pre-TC Low-level vortex center

- Monsoon vortex center

FIG. 12. The model-simulated (nonfiltered) $850-\mathrm{hPa}$ vorticity $\left(10^{-5} \mathrm{~s}^{-1}\right.$; shading, color bar on right) and winds ( $\mathrm{m} \mathrm{s}^{-1}$; vector, scale on the bottom). The pre-TC vortex center at midlevel (blue dot) and low level (red dot) interacting with the monsoon vortex (center with yellow dot) are plotted based on the filtered vortices at $500\left(10^{-5} \mathrm{~s}^{-1} ; 2-4\right.$ for black contours) and $850 \mathrm{hPa}\left(10^{-5} \mathrm{~s}^{-1} ; 0.5\right.$ for red dashed contour, and 2-4 for red solid contours). The 12-hourly variations of CTL simulations from (a) 0000 UTC 26 Sep to (e) 0000 UTC 28 Sep and of NoL simulations from (f) 0000 UTC 26 Sep to (j) 0000 UTC 28 Sep.

the pre-TC circulation and resulted in a westward shift of the MCV (Fig. 12c).

The interaction of monsoon and the MCV ultimately contributes to the low-level vortex enhancement and eventually the TC spinup. As in Figs. $12 \mathrm{c}$ and $12 \mathrm{~d}$, the eastward extension of the monsoon vortex flow toward the pre-TC midlevel vortex center is accompanied by VHTs (vorticity $>2 \times 10^{-5} \mathrm{~s}^{-1}$ ). Latent heating associated with convection in the enhanced background monsoon vorticity induces local positive anomalies of cyclonic vorticity. The successive local vortex merges into a larger-scale circulation, and the collocation of the mid and low-level vortex centers are what ultimately results in sufficient concentration of relative vorticity for formation to occur. While the northeasterly vertical shear surrounding this pre-TC circulation was quite strong $\left(>20 \mathrm{~m} \mathrm{~s}^{-1}\right)$ on 27 and 28 September both in the CTL simulation (Figs. 5c and 5d) and NCEP FNL 
(Figs. $5 \mathrm{~g}$ and $5 \mathrm{~h}$ ), the midlevel vortex center was temporarily displaced westward from the low-level vortex center at 1200 UTC 27 September (Fig. 12d). However, the pre-TC circulation became more vertically aligned on 27 September and the low-level vorticity strengthened beneath the midtropospheric vortex center associated with the diurnal extension of the monsoon synoptic vortex and the oceanic MCSs (Figs. 12d and 12e).

Even without land, the MCV in the NoL simulations (Figs. 12f and $12 \mathrm{~g}$ ) on 26 September is temporarily intensified by interacting with a very broad region of $850-\mathrm{hPa}$ vorticity to the northeast. Thus, the MCV remains rather stationary in the NoL simulations in contrast to the westward-moving MCV in the CTL simulations. Although a $500-\mathrm{hPa} \mathrm{MCV}$ is simulated in the NoL simulations, it remains separated from the monsoon vortex (Figs. 12h and 12i). Finally, the low-level vortex enhancement by the monsoon circulation, VHTs, and the subsequent upscale process below the MCV did not occur in the NoL simulations. In the absence of the monsoon-induced low-level vortex enhancement process, the wind shear environment was unfavorable (Figs. $5 \mathrm{~g}$ and $5 \mathrm{~h}$ ) in the NoL simulations. Because of the stronger northeasterly wind shear to the south, the midlevel vortex was significantly displaced westward and ultimately misaligned with the pre-TC low-level vortex (Fig. 12j), as will be described in more detail in section $5 \mathrm{c}$.

\section{c. MCV intensity and location associated with shear and low-level vortex enhancement}

This TC formation occurred adjacent to a large vertical wind shear zone to the south (Fig. 5; section 3b). To examine differences in vertical wind shear impacts with and without land simulations, a two-dimensional diagram of latitude location ( $y$ axis) versus intensity ( $x$ axis) of the filtered midlevel vorticity maximum, together with the filtered low-level vorticity maximum, is shown in Fig. 13. At the end of Stage I at 0000 UTC 26 September (section 5a), the no-land simulation had a weaker MCV that was farther south in a strong wind shear zone (e.g., Figs. 13a and 13b). However, the MCV intensity in the no-land simulation temporarily increased. During stage II, the disturbances in the control- and no-land simulations are at similar latitudes (around $14^{\circ} \mathrm{N}$ ) and are similarly impacted by unfavorable wind shears. In particular, midlevel vortex intensification in the absence of an intensifying low-level vortex (similar circle sizes during 27 September) in the no-land simulations (Figs. 13b, 13d, and 13f) indicates a vertical misalignment of the pre-TC circulation without a favorable monsoon interaction. In summary, the land-based convection can aid this TC formation by modulating the incipient MCV intensity and its location is more favorable in a weaker wind shear zone and a stronger monsoon vortex region.

\section{Conclusions}

The mesoscale processes leading to TC formation in the Atlantic that have been examined in theoretical and numerical studies (e.g., Montgomery et al. 2006; Nolan 2007; Wang 2014) generally assume that TC formation occurs over open-ocean conditions. In the western North Pacific, about $20 \%$ of the TCs develop over the South China Sea (Kim et al. 2011), which is surrounded by land. To understand the possible role of land-based convection in TC formation, this study analyzes WRF simulations of TS Mekkhala (2008) off the west coast of Luzon via sensitivity experiments in which the landmass over the northern Philippines is replaced by water. In these simulations, the land-based convection affects the intensity, vertical structure, and placement of the incipient midtropospheric mesoscale circulation that later developed into TS Mekkhala. The results presented here based on high-resolution WRF simulations with and without land are complementary to the multiscale analyses with the coarse-resolution global reanalysis data and satellite observations analyzed by Park et al. (2015).

Previous studies of western North Pacific TC formation (e.g., Harr et al. 1996) have emphasized the role of the monsoon trough. Three days prior to the preMekkhala formation, the two primary synoptic precursors are identified: the monsoon vortex and the elongated midlevel vortex that was approaching the Philippines. In this study, five sets of control- and no-land experiments indicate that a land-based MCS generated by differential heating between the land (Luzon) and the surrounding ocean during a period of strong monsoon flow played an essential role in the formation of the preMekkhala depression over the South China Sea (Fig. 9). In particular, daytime destabilization of the local environment and a sea-breeze circulation driven by land-sea differential heating (Park et al. 2011) promote intense land-based convection that interacts with oceanic convection in the monsoonal flow. The interaction results in a midtroposphere mesoscale vortex near the leading edge of the elongated precursor synoptic-scale circulation. The TC Mekkhala formation is also influenced by multiple diurnal processes, which include the large-scale monsoon diurnal perturbation (Huang et al. 2010), the local circulation over and around the Philippines (Park et al. 2011), and radiation cycle effects (Yang and Smith 2006).

The importance of deep vortical convection with enhanced low- to midlevel cyclonic circulations has been emphasized in several studies (Montgomery et al. 2006; Bell and Montgomery, 2010). The sensitivity 
(a) CTL

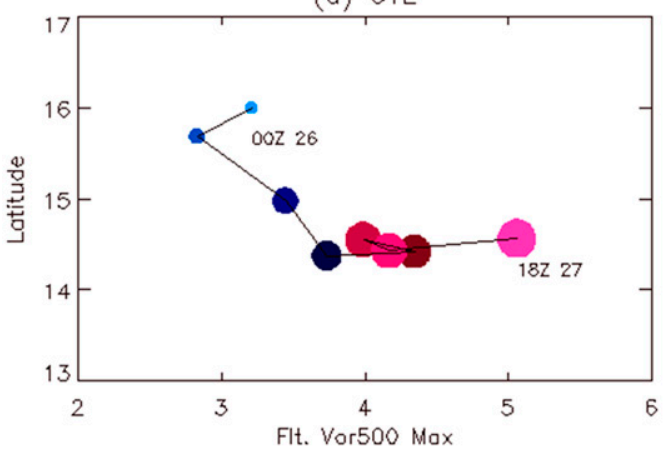

(c) CTL300

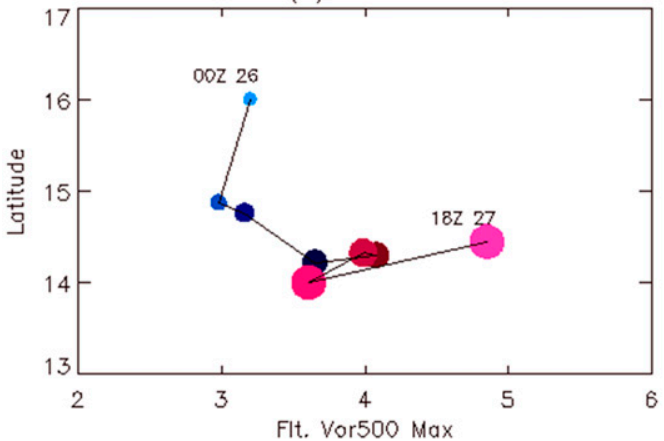

(e) CTL150

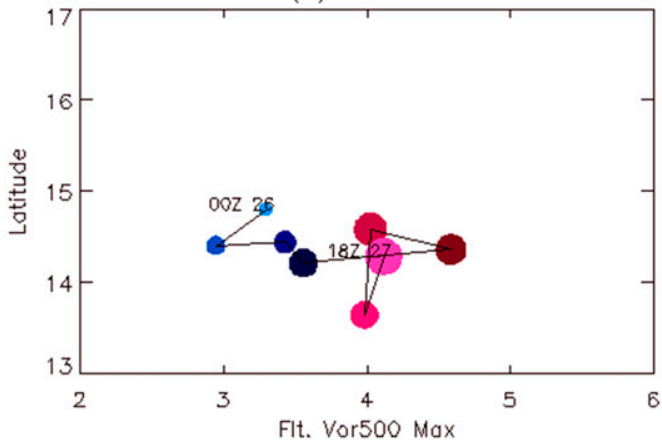

(b) NOL

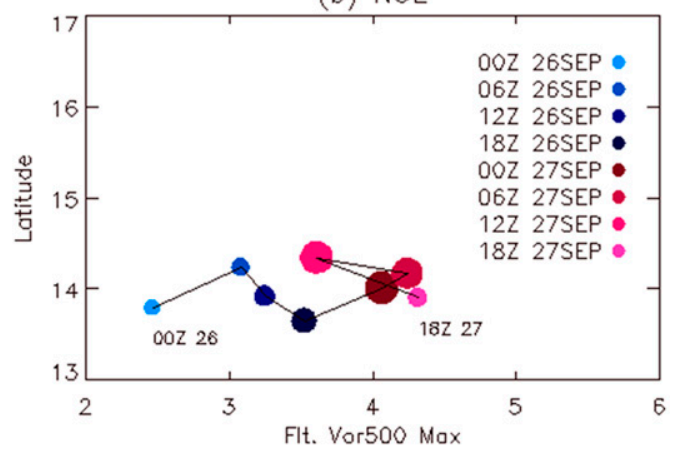

(d) NOL300

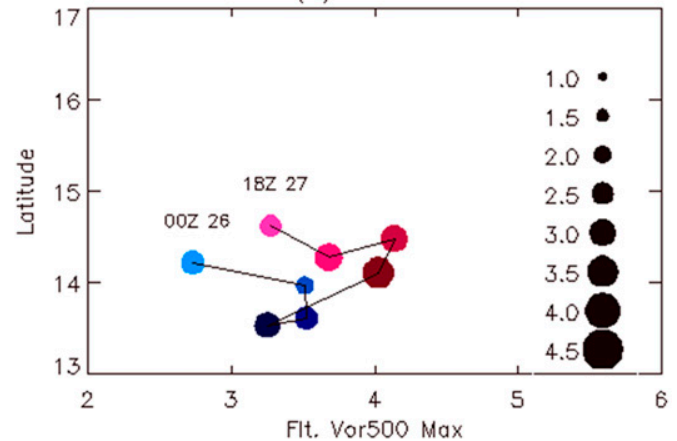

(f) CTL150

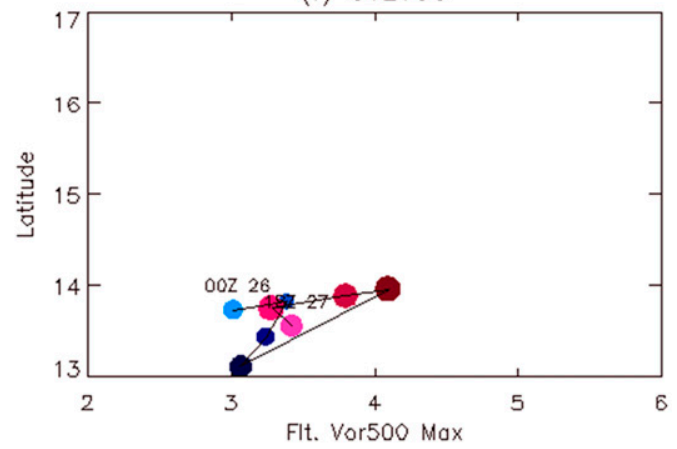

FIG. 13. Two-dimensional diagram of latitude location $\left(y\right.$ axis, $\left.{ }^{\circ} \mathrm{N}\right)$ vs intensity of the filtered midlevel vorticity maximum ( $x$ axis, $\left.10^{-5} \mathrm{~s}^{-1}\right)$, together the filtered low-level vorticity maximum $\left(10^{-5} \mathrm{~s}^{-1}\right.$ with the size of the circle) from the WRF simulations for (a) CTL, (b) NoL, (c) CTL300, (d) NoL300, (e) CTL150, and (f) NoL150. The different colors in the filled circles indicate the 6-hourly times from 0000 UTC 26 Sep to 1800 UTC 27 Sep [legend in (b)]. The different sizes of the circles indicate the magnitude of the filtered low-level vorticity maximum [legend in (d)].

experiments performed here demonstrate that the strong, focused land-based convection (instead of the more broadly distributed oceanic convection) has a prominent role in inducing multiple VHTs that strengthen the precursor midlevel vortex approaching the Philippines. The VHTs formed in the leading edge of the two convective systems merge with the preexisting oceanic convection (Fig. 12), resulting in a strong, moist MCV that is vertically aligned. Without the presence of the landbased MCS, the mesoscale vortex is weaker during the early formation stage. Although the midlevel vortex temporarily intensified, it failed to vertically align in the strong wind shear environment in the weaker monsoon vortex region.

The positive effect of the land-based MCS on TC formation is only possible due to cooperation with the monsoon convection and synoptic precursor. The stronger mesoscale vortex was located at a critical location that could interact with the monsoonal flow and the land-based MCS. We also emphasize here the positive phasing of the diurnal cycle, with the land-based convection occurring due to afternoon heating that then 
interacted with continued convective activity in the early morning over the ocean associated with a diurnal extension of the monsoon vortex (Huang et al. 2010; Park et al. 2011). In contrast, the incipient mesoscale circulation formed farther east in the no-land simulations as part of a broad region of oceanic convection that peaked only in the early morning, and further interaction with the monsoon vortex that appears critical for low-level circulation development did not occur.

This study is admittedly based on the numerical simulations of a TC formation. While the five sets of control-land and no-land experiments have confirmed the contributions of the land-based convection in the Mekkhala formation, it is of some concern how sensitive these simulations are to small changes in the prescribed cloud droplet number distribution. The results suggest that diurnal and land surface forcing was the primary mechanism by which the land-based convection contributed to genesis rather than specific microphysical processes associated with continental convection. Although none of the five no-land simulations formed a TC, the limited number of sensitivity simulations possibly contributed to uncertainty in the true possibility of TC formation in the absence of land. Consequently, the current study emphasizes the role of the land-based convection as aiding this Mekkhala formation, possibly as a necessary condition of TC formation.

Despite the underdevelopment, the WSM6 controlland runs also simulated the incipient $\mathrm{MCV}$ after the similar interaction with the oceanic and land-based convective systems, and the low-level development through the interaction with the monsoon circulation, consistent with the simulations presented here (not shown). These results are also sensitive to the initial conditions and the limited number of the model ensembles, suggesting that stochastic aspects of the convection play a role in the genesis process in addition to the synoptic and mesoscale forcing. Further studies are planned to investigate these factors in additional cases and to identify other aspects of the numerical model that contribute to the success or failure in predicting TC formation.

Convergence and the diurnal variation induced by Luzon are closely related to the evolution of both oceanic and land-based convection (Park et al. 2011). A storm does form in recently undertaken sensitivity tests in which the terrain of Luzon is removed but the land surface types are unchanged. This suggests that the island's orography is not a primary component of its influence on Mekkhala's development, which is a result that will be investigated in more detail in a follow-up study. Also, it is currently unclear whether the genesis of Mekkahala has implications for TC formation more generally. Even though this is only one case, it serves as a useful example to illustrate how land-based convection and the diurnal cycle can impact TC formation in coastal areas, and it deserves further study.

Acknowledgments. This work was funded by the Korea Meteorological Administration Research and Development Program under Grant KMIPA2015-1100. Michael M. Bell was supported by National Science Foundation CAREER Award AGS-1349881 and the Office of Naval Research Young Investigator Program Award N000141512601. Russell Elsberry was supported by the U.S. Office of Naval Research under Grant N141410275. The authors appreciate the ECMWF and the NCEP for providing the reanalysis datasets (YOTC and FNL, respectively) for this study. Finally, we sincerely thank the editor and three anonymous reviewers for their constructive comments and suggestions that helped improve this study.

\section{REFERENCES}

Beattie, J. C., and R. L. Elsberry, 2013: Horizontal structure of monsoon depressions in the western North Pacific at formation time. Geophys. Res. Lett., 40, 983-987, doi:10.1002/grl.50198.

Beljaars, A. C. M., 1995: The parameterization of surface fluxes in large-scale models under free convection. Quart. J. Roy. Meteor. Soc., 121, 255-270, doi:10.1002/qj.49712152203.

Bell, M. M., and M. T. Montgomery, 2010: Sheared deep vertical convection in pre-depression Hagupit during TCS08. Geophys. Res. Lett., 37, L06802, doi:10.1029/2009GL042313.

Chen, F., and J. Dudhia, 2001: Coupling an advanced land surfacehydrology model with the Penn State-NCAR MM5 modeling system. Part I: Model implementation and sensitivity. Mon. Wea. Rev., 129, 569-585, doi:10.1175/1520-0493(2001)129<0569: CAALSH $>2.0 . \mathrm{CO} ; 2$.

Davis, C. A., and D. A. Ahijevych, 2012: Mesoscale structural evolution of three tropical weather systems observed during PREDICT. J. Atmos. Sci., 69, 1284-1305, doi:10.1175/ JAS-D-11-0225.1.

Elsberry, R. L., and P. A. Harr, 2008: Tropical Cyclone Structure (TCS08) field experiment: Science basis, observational platforms, and strategy. Asia-Pac. J. Atmos. Sci., 44, 209-231.

Gray, W. M., 1968: Global view of the origin of tropical disturbances and storms. Mon. Wea. Rev., 96, 669-700, doi:10.1175/ 1520-0493(1968)096<0669:GVOTOO >2.0.CO;2.

- 1975: Tropical cyclone genesis. Dept. of Atmospheric Science, Colorado State University Paper CSU-ATSP-234, 121 pp.

Harr, P. A., R. L. Elsberry, and J. C. L. Chan, 1996: Transformation of a large monsoon depression to a tropical storm during TCM-93. Mon. Wea. Rev., 124, 2625-2643, doi:10.1175/ 1520-0493(1996)124<2625:TOALMD>2.0.CO;2.

Hendricks, E. A., M. T. Montgomery, and C. A. Davis, 2004: The role of "vortical" hot towers in the formation of Tropical Cyclone Diana (1984). J. Atmos. Sci., 61, 1209-1232, doi:10.1175/1520-0469(2004)061<1209:TROVHT>2.0.CO;2.

Heymsfield, G. M., L. Tian, A. J. Heymsfield, L. Li, and S. Guimond, 2010: Characteristics of deep tropical and subtropical convection from nadir-viewing high-altitude airborne Doppler radar. J. Atmos. Sci., 67, 285-308, doi:10.1175/2009JAS3132.1.

Ho, C.-H., M.-S. Park, Y.-S. Choi, and Y. N. Takayabu, 2008: Relationship between intraseasonal oscillation and diurnal 
variation of summer rainfall over the South China Sea. Geophys. Res. Lett., 35, L03701, doi:10.1029/2007GL031962.

Hong, S.-Y., Y. Noh, and J. Dudhia, 2006: A new vertical diffusion package with an explicit treatment of entrainment processes. Mon. Wea. Rev., 134, 2318-2341, doi:10.1175/MWR3199.1.

Huang, W.-R., J. C. L. Chan, and S.-Y. Wang, 2010: A planetaryscale land-sea breeze circulation in East Asia and the western North Pacific. Quart. J. Roy. Meteor. Soc., 136, 1543-1553, doi:10.1002/qj.663.

Huffman, G. J., and Coauthors, 2007: The TRMM Multisatellite Precipitation Analysis (TMPA): Quasi-global, multiyear, combined-sensor precipitation estimates at fine scales. J. Hydrometeor., 8, 38-55, doi:10.1175/JHM560.1.

Johnson, R. H., S. L. Aves, P. E. Ciesielski, and T. D. Keenan, 2005 Organization of oceanic convection during the onset of the 1998 East Asian summer monsoon. Mon. Wea. Rev., 133, 131148, doi:10.1175/MWR-2843.1.

Kain, J. S., 2004: The Kain-Fritsch convective parameterization: An update. J. Appl. Meteor., 43, 170-181, doi:10.1175/ 1520-0450(2004)043<0170:TKCPAU>2.0.CO;2.

Kim, H.-S., J.-H. Kim, C.-H. Ho, and P.-S. Chu, 2011: Pattern classification of typhoon tracks using the fuzzy $c$-means clustering method. J. Climate, 24, 488-508, doi:10.1175/2010JCLI3751.1.

Kim, J.-H., C.-H. Ho, H.-S. Kim, C.-H. Sui, and S. K. Park, 2008: Systematic variation of summertime tropical cyclone activity in the western North Pacific in relation to the Madden-Julian oscillation. J. Climate, 21, 1171-1191, doi:10.1175/2007JCLI1493.1.

Lander, M. A., 1994: Description of a monsoon gyre and its effect on the tropical cyclones in the western North Pacific during August 1991. Wea. Forecasting, 9, 640-654, doi:10.1175/ 1520-0434(1994)009<0640:DOAMGA > 2.0.CO;2.

Mlawer, E. J., S. J. Taubman, P. D. Brown, M. J. Iacono, and S. A. Clough, 1997: Radiative transfer for inhomogeneous atmospheres: RRTM, a validated correlated-k model for the longwave. J. Geophys. Res., 102, 16 663-16 682, doi:10.1029/ 97JD00237.

Mohr, K. I., and E. J. Zipser, 1996: Mesoscale convective systems defined by their $85-\mathrm{GHz}$ ice scattering signature: Size and intensity comparison over tropical oceans and continents. Mon. Wea. Rev., 124, 2417-2437, doi:10.1175/ 1520-0493(1996)124<2417:MCSDBT > 2.0.CO;2.

Montgomery, M. T., M. E. Nicholls, T. A. Cram, and A. B. Saunders, 2006: A vortical hot tower route to tropical cyclogenesis. J. Atmos. Sci., 63, 355-386, doi:10.1175/JAS3604.1.

— , and Coauthors, 2012: The Pre-Depression Investigation of Cloud-Systems in the Tropics (PREDICT) experiment: Scientific basis, new analysis tools, and some first results. Bull. Amer. Meteor. Soc., 93, 153-172, doi:10.1175/BAMS-D-11-00046.1.

Noh, Y. W., W. G. Cheon, S. Y. Hong, and S. Raasch, 2003: Improvement of the K-profile model for the planetary boundary layer based on large eddy simulation data. Bound.-Layer Meteor., 107, 401-427, doi:10.1023/A:1022146015946.

Nolan, D. S., 2007: What is the trigger for tropical cyclogenesis? Aust. Meteor. Mag., 56, 241-266.
Park, M.-S., and R. L. Elsberry, 2013: Latent heating and cooling rates in developing and nondeveloping tropical disturbances during TCS-08: TRMM PR and ELDORA retrievals. J. Atmos. Sci., 70, 15-35, doi:10.1175/JAS-D-12-083.1.

—, C.-H. Ho, J. Kim, and R. L. Elsberry, 2011: Diurnal circulations and their multi-scale interaction leading to rainfall over the South China Sea upstream of the Philippines during intraseasonal monsoon westerly wind bursts. Climate Dyn., 37, 1483-1499, doi:10.1007/s00382-010-0922-z.

— A. B. Penny, R. L. Elsberry, B. J. Billings, and J. D. Doyle, 2013: Latent heating and cooling rates in developing and nondeveloping tropical disturbances during TCS-08: Radarequivalent retrievals from mesoscale numerical models and ELDORA. J. Atmos. Sci., 70, 37-55, doi:10.1175/JAS-D-11-0311.1.

, H.-S. Kim, C.-H. Ho, R. L. Elsberry, and M.-I. Lee, 2015: Tropical Cyclone Mekkhala's (2008) formation over the South China Sea: Mesoscale, synoptic-scale, and large-scale contributions. Mon. Wea. Rev., 143, 88-110, doi:10.1175/MWR-D-14-00119.1.

Penny, A. B., P. A. Harr, and M. M. Bell, 2015: Observations of a nondeveloping tropical disturbance in the western North Pacific during TCS-08 (2008). Mon. Wea. Rev., 143, 2459-2484, doi:10.1175/MWR-D-14-00163.1.

Reed, R. J., and E. E. Recker, 1971: Structure and properties of synoptic-scale wave disturbances in the equatorial western Pacific. J. Atmos. Sci., 28, 1117-1133, doi:10.1175/ 1520-0469(1971)028<1117:SAPOSS > 2.0.CO;2.

Ritchie, E. A., and G. J. Holland, 1997: Scale interactions during the formation of Typhoon Irving. Mon. Wea. Rev., 125, 1377-1396, doi:10.1175/1520-0493(1997)125<1377:SIDTFO > 2.0.CO;2.

Skamarock, W. C., and Coauthors, 2008: A description of the Advanced Research WRF version 3. NCAR Tech Note NCAR/TN-475+STR, 113 pp., doi:10.5065/D68S4MVH.

Snively, D. V., and W. A. Gallus Jr., 2014: Prediction of convective morphology in near-cloud-permitting WRF model simulations. Wea. Forecasting, 29, 130-149, doi:10.1175/WAF-D-13-00047.1.

Tao, W. K., S. Lang, J. Simpson, C.-H. Sui, B. Ferrier, and M.-D. Chou, 1996: Mechanisms of cloud-radiation interaction in the tropics and midlatitudes. J. Atmos. Sci., 53, 2624-2651, doi:10.1175/1520-0469(1996)053<2624:MOCRII >2.0.CO;2.

Thompson, G., R. M. Rasmussen, and K. Manning, 2004: Explicit forecasts of winter precipitation using an improved bulk microphysics scheme. Part I: Description and sensitivity analysis. Mon. Wea. Rev., 132, 519-542, doi:10.1175/ 1520-0493(2004)132<0519:EFOWPU>2.0.CO;2.

Wang, Z., 2014: Role of cumulus congestus in tropical cyclone formation in a high-resolution numerical model simulation. J. Atmos. Sci., 71, 1681-1700, doi:10.1175/JAS-D-13-0257.1.

— M. T. Montgomery, and T. J. Dunkerton, 2010: Genesis of pre-Hurricane Felix (2007). Part II: Warm core formation, precipitation evolution, and predictability. J. Atmos. Sci., 67, 1730-1744, doi:10.1175/2010JAS3435.1.

Yang, S., and E. A. Smith, 2006: Mechanisms for diurnal variability of global tropical rainfall observed from TRMM. J. Climate, 19, 5190-5226, doi:10.1175/JCLI3883.1. 